\title{
NATURAL GAS LIQUIDS EXTRACTION RIGHTS IN ALBERTA: AN EVOLVING LANDSCAPE
}

\author{
DAVE Guichon, BernetTe Ho, AND RoBert FroeHLiCH*
}

\begin{abstract}
Alberta's natural gas liquids (NGLs) industry commenced development in the 1960s and, with the support of the Alberta government, expanded rapidly in the subsequent decades. Over time each of the major natural gas transmission systems in Alberta developed its own protocol in respect of NGL extraction entitlement and procedures. In the case of the NOVA Gas Transmission Ltd. (NGTL) pipeline system, such a protocol was developed by way of convention, and has never been formalized in the NGTL tariff. On several occasions the Alberta Energy and Utilities Board (EUB), and its predecessors, examined the issue of NGL ownership and associated extraction, but significant issues remained. In 2007, the EUB undertook an inquiry regarding matters relating to NGL ownership and extraction from the common stream of natural gas that flows through EUB regulated transmission systems and facilities. The EUB's decision in this respect was released in February 2009. This article provides background information on the NGL extraction industry, outlines the regulatory history relating to NGL ownership and extraction, reviews the decision released by the EUB following the inquiry, considers related jurisdictional questions raised while the inquiry was ongoing, and considers the future of NGL ownership and extraction rights within the province of Alberta.
\end{abstract}

La mise en valeur du secteur des liquides de gaz naturel (LGN) de l'Alberta commença 1960 et, grâce au soutien du gouvernement provincial, ce secteur se développa rapidement au cours des décennies suivantes. Au fil du temps, les principaux réseaux de collecte et de distribution de gaz naturel en Alberta développèrent tous leur propre protocole en ce qui concerne le droit d'extraire les LGN et les procédures pertinentes. Dans le cas du réseau de gazoducs de NOVA Gas Transmission Ltd. (NGTL), le protocole reposait sur des usages et n'avait jamais été officiellement incorporé dans le tarif de la société. Le Alberta Energy and Utilities Board (EUB), et les organismes qui l'ont précédé examinèrent, à plusieurs reprises, la question de la propriété des LGN et des extractions connexes, mais il demeure que des questions importantes restèrent sans réponse. En 2007, le EUB décida de faire une enquête sur la question de la propriétéet l'extraction de LGN du courant commun du gaz naturel qui passe dans les réseaux et installations de transmission officiels du EUB. La décision du EUB à cet égard fut annoncée en février 2009. Cet article donne des renseignements de base sur le secteur de l'extraction de LGN, énonce les grandes lignes de l'historique de la réglementation en ce qui concerne la propriété et l'extraction de LGN, examine les décisions publiées par le EUB après l'enquête, tient compte des questions pertinentes de juridiction soulevées pendant l'enquête et examine l'avenir des droits de propriétéet d'extraction des $L G N$ dans la province de l'Alberta.

\section{TABLE OF CONTENTS}

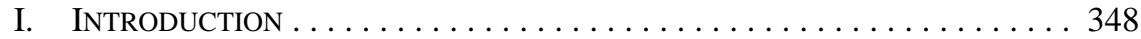

II. BACKGROUND . . . . . . . . . . . . . . . . . . . . . . . . 349

A. NGL EXTRACTION IN ALbERTA . . . . . . . . . . . . . . . . . . . . . 349

B. NGL EXTRACTION ENTITLEMENT $\ldots \ldots \ldots \ldots \ldots \ldots \ldots \ldots \ldots \ldots$

C. CONTRACTUAL NGL EXTRACTION RightS ARRANGEMENTS . . . . 353

D. NGTL EXTRACTION RIGHTS CONVENTION . . . . . . . . . . 354

III. Genesis Of THE INQUIRY $\ldots \ldots \ldots \ldots \ldots \ldots \ldots \ldots \ldots \ldots \ldots \ldots \ldots \ldots \ldots \ldots$

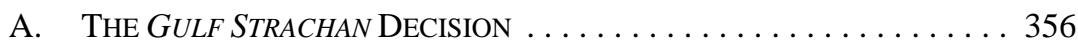

B. THE SOLEX DECISION .......................... 358

C. THE NECTF REPORT $\ldots \ldots \ldots \ldots \ldots \ldots \ldots \ldots \ldots \ldots \ldots \ldots \ldots$

Macleod Dixon LLP. The authors would also like to thank Dan Ronsky and Gord Milne of TransCanada Pipelines Limited for their input and advice on the operational aspects of NGL extraction on the NGTL System. 
IV. THE INQUIRY PROCEEDINGS AND DECISION $\ldots \ldots \ldots \ldots \ldots \ldots \ldots \ldots . \ldots . \ldots . \ldots . \ldots . \ldots$

A. The Regulator . . . . . . . . . . . . . . . . . . . . . . . . . . . . . . 364

B. THE PARTICIPANTS ... . . . . . . . . . . . . . . . . . . 365

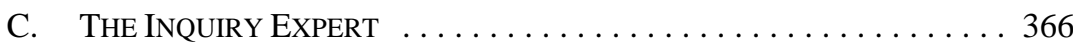

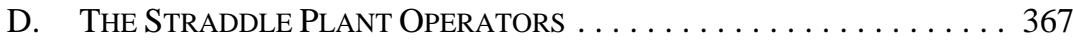

E. THE NGTL CONVENTION ISSUE . . . . . . . . . . . . . . . . . . . . . . 369

V. THE NGTL JURISDICTION DECISION . . . . . . . . . . . . . . . 378

VI. Post-INQUiRy DEVELOPMENTS AND EXPECTATIONS . . . . . . . . . . . 379

A. NGTL CONVENTION MODIFICATION . . . . . . . . . . . . 379

B. ATCO SyStem EXTRACTION RightS PRotocol . . . . . . . . . . . 384

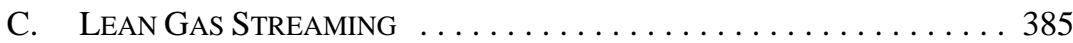

D. SidE-STREAMING AND CO-STREAMING . . . . . . . . . . . . . . 385

\section{INTRODUCTION}

This article examines recent regulatory developments affecting entitlement to extract natural gas liquids (NGLs) entrained in natural gas being transported through regulated pipeline systems in Alberta as well as the implications of those developments for natural gas producers and shippers, and operators of straddle plants and other NGL extraction facilities.

The article is comprised of three parts. The first part provides some background on the NGL extraction business in Alberta, together with a high level review of the development of current regulated pipeline NGL extraction practices in Alberta, and the legal principles relevant thereto.

The second part of the article, consisting of Parts III through V, discusses the Inquiry into Natural Gas Liquids Extraction Matters (the Inquiry) undertaken by the former Alberta Energy and Utilities Board (EUB) in 2007, including a review of the regulatory history leading up to the initiation of the Inquiry, an overview of the various interests and perspectives of the Inquiry participants, and the EUB's 4 February 2009 decision in the matter. ${ }^{1}$ This portion of the article also briefly discusses the 26 February 2009 decision of the National Energy Board (NEB) ${ }^{2}$ to accept jurisdiction over the Nova Gas Transmission Ltd. (NGTL) natural gas gathering and transmission system (the NGTL System) and the potential impact this decision may have on the Inquiry Decision.

The final part of the article considers the NGL extraction rights attribution and contracting practices changes that can be expected to occur as a result of the Inquiry Decision, with a focus on the implementation of NGTL's proposed NGL Extraction Model for allocating, tracking, and exercising NGL extraction rights on the NGTL System (the NEXT Model). It also discusses transition processes and timing.

1 Inquiry into Natural Gas Liquids (NGL) Extraction Matters (4 February 2009), EUB Decision 2009-009, online: ERCB <http://www.ercb.ca/docs/documents/decisions/2009/2009-009.pdf> [Inquiry Decision]. TransCanada Pipelines Limited (February 2009), Reasons for Decision GH-5-2008 (NEB), online: National Energy Board (NEB) <https://www.neb-one.gc.ca/ll-eng/Livelink.exe/fetch/2000/90464/ 90550/90715/518313/518500/549090/549124/A1I9K3_-_GH-5-2008_Reasons_for_Decision.pdf? nodeid=549125\&vernum $=0>$ [NGTL Jurisidiction Decision $]$. 


\section{BACKGROUND}

Comprehensive discussions of the history of Alberta's NGL industry can be found in both the Inquiry Decision and the September 2005 Report of the Natural Gas Liquid Extraction Convention Task Force (NECTF) referred to therein. ${ }^{3}$ An abbreviated review of some of the more salient elements of those discussions is as follows.

\section{A. NGL EXTRACtion in Alberta}

Natural gas is comprised primarily of methane, but also typically contains a variety of other substances in lesser quantities. Among the common secondary constituents found in natural gas are ethane (also referred to as $\mathrm{C}_{2}$ ) propane (also referred to as $\mathrm{C}_{3}$ ), normal and iso butanes (also referred to as $\mathrm{C}_{4}$ ) and pentanes and heavier hydrocarbons (also referred to as $\mathrm{C}_{5}+$ ), all of which are commonly referred to as natural gas liquids or NGLs. NGLs are heavier than methane, but will remain in a gaseous state within a fairly broad band of pressures and temperatures. Ethane is the lightest and most predominant NGL, while pentanes plus are the heaviest of the NGLs and the least likely to remain in a gaseous state in significant quantities under typical natural gas handling conditions. The composition of natural gas varies from reservoir to reservoir, and the concentration of NGLs in a natural gas production stream can range from quite significant (rich gas) to relatively insignificant (lean gas).

In addition to having a higher energy content than methane, NGLs have different commercial uses that justify separation from the natural gas stream and further "fractionation" into distinct products. Ethane is used primarily as feedstock for the production of ethylene, which is then further processed into a variety of industrial and consumer products; propane is used as both a multi-purpose fuel and a petrochemical industry feedstock; butanes are used in the blending of gasoline and for other refinery processes; and pentanes plus are currently used mainly as a diluent to reduce the viscosity of heavy crude oil and bitumen to facilitate pipeline transportation.

The first NGL extraction activity in Alberta was undertaken at field gas processing plants for the primary purpose of removing heavier NGLs from natural gas streams to avoid pipeline transmission condensation issues. Construction of NGL extraction "straddle plants" on main gas transmission lines commenced in the 1960s and the industry grew rapidly in the ensuing decades, with the Alberta Government becoming particularly supportive of the industry commencing in the 1970s. With a focus on economic diversification and realization of greater value from the Province's natural resources, the Government undertook a series of initiatives to encourage the development of an Alberta-based petrochemical industry utilizing ethane and other NGLs extracted from Alberta gas production. In particular, through the use of directives such as the Alberta Ethane Policy, ${ }^{4}$ the Alberta Government has

3 See NGL Extraction Convention Task Force, NGL Extraction: Current Convention and Alternatives (September 2005), online: TransCanada <http://www.transcanada.com/Alberta/regulatory_info/active_ rates_pdfs/2005_09_28_TTFP_Resolution_T2004_04_NGL_Extraction_Convention.pdf $>$ [NECTF Report].

4 See Energy Resources Conservation Board (ERCB), Alberta Ethane Policy: Report on Implementation, Report D88 (Calgary: Energy Resources Conservation Board, 1988), online: ERCB <http://www.ercb. ca/docs/documents/reports/r88d-EthanePolicy.pdf $>$. 
promoted increased ethane recovery, which has in turn led to considerable growth in the ethylene production business over the past four decades. Although a significant portion of Alberta's propane and butane is shipped to Eastern Canada and the United States, substantially all ethane and pentanes plus extracted in Alberta are used in the Province. In 2007 the value of Alberta NGL production was CDN\$9.5 billion, representing over 23 percent of the total value of natural gas and NGLs combined, ${ }^{5}$ and the Alberta Department of Energy estimates that Alberta's petrochemical industry currently contributes over CDN\$15 billion per year to the Province's economy, and directly employs over 7,500 workers. ${ }^{6}$

Extraction of NGLs from a natural gas stream may involve extraction of just heavier NGLs such as pentanes plus, extraction of a " $\mathrm{C}_{3}+$ " mix comprised of propane and heavier NGLs, or extraction of a " $\mathrm{C}_{2}+$ " mix comprised of the full suite of NGLs. Alberta currently has more than 500 field gas processing plants with some level of NGL extraction capability, ${ }^{7}$ but only a relatively small number of these field plants have any significant $\mathrm{C}_{2}+$ or $\mathrm{C}_{3}+$ extraction capability, and most ethane (76 percent) and propane (51 percent) is extracted at straddle plants located on main gas transmission lines. ${ }^{8}$

There are currently nine recognized straddle plants in Alberta, ${ }^{9}$ six on the NGTL System, and three on the ATCO Gas and Pipelines Ltd. gas transmission system (the ATCO System), which is operated by the company's ATCO Pipelines division (ATCO Pipelines). ${ }^{10}$ The other two major regulated gas transmission systems in Alberta, the AltaGas Utilities Inc. (AltaGas Utilities) system (the AltaGas System) and the Alliance Pipeline Limited Partnership (Alliance) system (the Alliance System), do not currently host NGL extraction activities in Alberta. Of these four systems (collectively, the Alberta Gas Systems), the ATCO System and the AltaGas System are intra-provincial systems regulated by the Alberta Utilities Commission (the AUC), the Alliance System is an interprovincial system regulated by the NEB, and the NGTL System is in transition from regulation by the AUC to regulation by the NEB (see Part V, The NGTL Jurisdiction Decision, below). The Alliance System is an NEB regulated "bullet" system that, in conjunction with a U.S. counterpart system, carries rich gas from northeastern British Columbia and northwestern Alberta to the Chicago area, with NGL extraction currently occurring only at a point near the terminus of the U.S. system in Illinois, but Alliance was nonetheless considered in the Inquiry because it was then assessing a proposal for the development of an Alberta extraction facility that could have been subject to EUB jurisdiction.

The NGL extraction industry in Alberta is currently being affected by a number of developments that could combine to result in significant excess extraction capacity in the Province, particularly for straddle plants located near export points on the NGTL System. Evidence submitted by a number of Inquiry participants indicates that a combination of decreasing Alberta natural gas production and increasing natural gas consumption within the

Inquiry Decision, supra note 1 at 9.

Alberta Energy, Petrochemicals in Alberta, online: Alberta Energy <http://www.energy.gov.ab.ca/ Petrochemical/pdfs/Petrochemicals_brochure_overview.pdf $>$.

Inquiry Decision, supra note 1 at 18.

Ibid. at 5.

Ibid. at 8.

Ibid. at 9 . 
Province can be expected to result in drastic declines in the amount of gas available for processing at export point straddle plants, with utilization rates dropping precipitously over the next decade, and with Alberta sourced ethane and other NGL supply decreasing accordingly. The problem is exacerbated by the fact that a significant portion of anticipated new Alberta gas production (e.g. coal bed methane) is lean gas, and accordingly not very prospective for NGL extraction. This projected deterioration in extraction feedstock supply received considerable attention in the Inquiry. ${ }^{11}$ Attracting rich ex-Alberta gas to the NGTL System from Alaska, the Mackenzie Delta, and Northeastern British Columbia is seen as key to preserving the vitality of Alberta's NGL extraction and associated petrochemical industries, and the EUB acknowledged that in its deliberations. ${ }^{12}$ Views expressed by the State of Alaska among others indicated that retained ownership and control of entrained NGLs could be a significant factor in determining whether existing Alberta natural gas transportation and processing infrastructure is incorporated in northern gas transportation plans. $^{13}$

\section{B. NGL EXTRACTION ENTITLEMENT}

Each of the Alberta Gas Systems is a common carrier system that transports commingled natural gas on behalf of multiple shippers under general terms and conditions set out in a tariff approved by the governing regulatory authority. Although there has been no definitive Canadian judicial consideration of the legal characterization of these carriage arrangements, their terms are generally consistent with a characterization as an arrangement in the nature of a bailment for hire with authorization to commingle. ${ }^{14}$ There is some question as to whether a possessory arrangement involving the commingling of fungible goods can technically be characterized as a bailment under Canadian common law, ${ }^{15}$ but in the context of Alberta Gas System transportation arrangements the alternative characterization of a receipt point disposition coupled with a corresponding delivery point re-acquisition is inconsistent with the intention evidenced by both the governing documentation and established industry practice. It is commonly accepted that system operators are intended to take only "custody and control" of the natural gas delivered to them for carriage, and that title to that natural gas is intended to remain with the collective shippers. ${ }^{16}$ Although each shipper's proprietary interest may change when it commingles its natural gas with the natural

\footnotetext{
Ibid. at 27-37.

Ibid. at 36.

Ibid. at 40-41.

Bailment is defined as "[a] delivery of personal property by one person (the bailor) to another (the bailee) who holds the property for a certain purpose under an express or implied-in-fact contract. Unlike a sale or gift of personal property, a bailment involves a change in possession but not in title.” A "bailment for hire" results when the bailee is compensated by the bailor (Black's Law Dictionary, 8th ed., s.v. "bailment”).

15 See Chris Simard \& Andrew Lamb, “An Introduction to Various Issues Surrounding the Ownership of Storage/Pipeline Gas” (2006) 44 Alta. L. Rev. 513 at 518-21; Bruce Welling, Property in Things in the Common Law System (Adelaide: Hyde Park Press, 1996) at 282-83; Bruce Ziff, Principles of Property Law, 4th ed. (Toronto: Thomson Canada, 2006) at 298.

16 See e.g. Gas Transportation Tariff of Nova Gas Transmission Ltd., online: TransCanada <http://www.trans canada.com/Alberta/info_postings/tariff/index.html> at para. 6.1 as well as Appendix C, which sets out the procedures for "title transfers” of “Customer's Inventory” [NGTL Tariff]. See also ATCO Pipelines, Transportation Service Regulations, online: ATCO <http://www.atcopipelines.com/ NR/rdonlyres/AEFA121E-9C93-4DAF-936C-5EA97443212D/0/TransportationServiceRegulations 2006.pdf> at para. 2.5, “Title or Interest in the Gas" [ATCO Tariff].
} 
gas of other shippers, that should not affect the characterization of the transporter as a bailee of the commingled stream of gas received by it for carriage.

Because the natural gas carriage arrangement involves authorized commingling, a shipper delivering natural gas into an Alberta Gas System has its direct ownership interest in that natural gas converted to an entitlement to a proportional share of the commingled natural gas stream. Again there is no Canadian jurisprudential guidance on the exact legal characterization of this entitlement, but the academic suggestion that the shippers own the commingled stream as tenants in common ${ }^{17}$ has logical appeal, and is consistent with the historical industry approach to these carriage arrangements. Simplistically expressed, when a shipper contributes natural gas to a commingled stream it becomes entitled to a corresponding ownership interest in that commingled stream, subject to the terms of the common ownership arrangement established by the tariff and service contracts and procedures applicable to the particular transportation system. The precise terms of this common ownership arrangement can be expected to vary from system to system having regard to applicable transportation tariffs, contracts, and procedures.

Of note in the assessment of Alberta Gas System common stream ownership is the role and treatment of "line pack" gas, which is the quantity of gas that is continuously maintained in the system for operational purposes. Among other things, line pack effectively eliminates the need to time the physical movement of gas, allowing a shipper to recover gas out of the system basically contemporaneously with its supply of gas into the system, irrespective of the time it would take to physically move that gas from the receipt point to the delivery point. Base line pack is typically purchased for the system by the transporter, with associated costs paid by the transporter and factored into the tolls charged to shippers for transportation service. If the transporter was to discontinue receiving gas into the system, and settle its delivery obligations to its shippers, the line pack remaining in the system would belong to it. Although this analysis of ultimate line pack entitlement might invite a conclusion that most of the gas in the system at any given time actually belongs to the transporter, and not the collective shippers, the historical approach of transporters and shippers alike has been to essentially disregard the line pack factor in considering ownership of the common stream. ${ }^{18}$ One explanation for this may be the dynamic nature of the transportation undertaking, with gas continually flowing into the system at receipt points and out of the system at delivery points. Under these circumstances, the base line pack supply may be viewed as a "float" quantity of gas that is lent to the system shippers by the transporter, and is recoverable out of gas in the system at such time as it is no longer required for operational purposes. In any event, whatever the reconciliation analysis may be, the clearly established practice is to treat the shippers as the collective owners of the common stream for so long as they are continuing to move gas through the system.

As the acknowledged owners of the commingled gas stream, the collective shippers are also the owners of any NGLs entrained in that stream, and accordingly have the inherent right to extract those NGLs from the stream, subject to the terms of the applicable

Of note in this respect is that the line pack factor was raised as an issue in the Inquiry hearing proceedings, but was given no material consideration in those proceedings and was not mentioned in the Inquiry Decision. 
carriage/bailment arrangement. Since the transporter is granted custody and control of all shippers' gas in its system, and as custodian of the commingled stream, will presumably want to ensure that the respective NGL property rights of the individual shippers are appropriately defined, recognized, and balanced, the exercise of an individual shipper's inherent NGL extraction entitlement will require the concurrence and co-operation of the transporter, and will at least conceptually need to be managed so as to ensure equitable treatment of all shippers. As a practical matter, this inherent right to separately recover a proportionate share of entrained NGLs is typically transferred or assigned to a straddle plant operator or other person in a position to make effective use of it, and is then exercised in accordance with whatever tariff terms and/or practices and procedures as may have been established by the transporter for that purpose.

The terms of the contract under which a shipper grants a straddle plant or other NGL extraction facility operator the right to exercise the shipper's NGL extraction entitlement (an Extraction Contract) were at one time relatively uniform, but are now quite varied. A traditional Extraction Contract would typically provide the grantee with a right to extract NGLs at its discretion, subject to an obligation to (1) supply back to the system a quantity of "shrinkage" or "make-up" gas (make-up gas) having a heat content equal to the heat content of the NGLs extracted, and (2) pay the shipper a negotiated cash "premium" based on the quantity of $\mathrm{C}_{3}+$ extracted. As the industry has evolved, the increased sophistication and creativity of its various participants has resulted in a broad range of approaches to Extraction Contract terms and compensation arrangements.

\section{Contractual NGL EXTRACTION Rights ARRANGEMENTS}

On three of the four Alberta Gas Systems (the ATCO System, the AltaGas System, and the Alliance System) entitlement to extract entrained NGLs is dealt with by way of express contract or tariff terms. In each such case the shipper is required to transfer some or all of its NGL extraction rights to the transporter or a designate of the transporter, effectively eliminating any opportunity to exercise or market those rights independently.

The ATCO Transportation Service Regulations ${ }^{19}$ provide that ATCO Pipelines is entitled to remove hydrocarbon components (i.e. NGLs) from the common stream with title to the extracted hydrocarbons passing to ATCO Pipelines upon such removal. ${ }^{20}$ There are currently three straddle plants on the ATCO System (Edmonton, Fort Saskatchewan, and Villeneuve), all of which are owned and operated by ATCO Midstream Ltd., an affiliate of ATCO Pipelines. As compensation for NGLs extracted by it, ATCO Midstream provides make-up gas having an energy content equal to the energy content of the NGLs extracted. ${ }^{21}$

Although there are currently no NGL extraction facilities located on the AltaGas System, the AUC approved AltaGas Transportation Service Regulations for Rate 10 - Producer 
Transportation Service, ${ }^{22}$ which provide NGL extraction rights to AltaGas Utilities on terms substantially the same as those applicable to ATCO Pipelines under the ATCO Tariff. ${ }^{23}$

NGL extraction on the Alliance System is dealt with by way of a somewhat unique arrangement under which each shipper is required to enter into an Extraction Agreement with Aux Sable Liquid Products LP (Aux Sable), providing Aux Sable the exclusive right to extract and take title to that shipper's proportionate share of NGLs entrained in the Alliance System common stream. If Aux Sable exercises this right, it is required to provide make-up gas with a heating value equal to the heating value of the NGLs extracted, but it is not otherwise required to compensate the shipper for such NGLs. ${ }^{24}$ Aux Sable is affiliated with Alliance, and is also affiliated with Alliance Pipeline L.P., the U.S. limited partnership that owns the U.S. segment of the Alliance Pipeline System. The arrangements under which Aux Sable was provided with exclusive NGL extraction rights on both the Canadian and U.S. segments of the Alliance Pipeline System were part of a comprehensive suite of arrangements established to facilitate the development of the Alliance Pipeline System in the late 1990s. ${ }^{25}$ These arrangements included, among other things, a commitment on the part of Aux Sable to manage the heat content of gas being delivered out of the Alliance Pipeline System in Illinois, so as to ensure compliance with heat content restrictions on certain downstream pipeline systems. ${ }^{26}$ Aux Sable has developed a NGL extraction facility straddling the Alliance Pipeline System near its terminus in Illinois, but, as noted earlier, there is not currently any NGL extraction taking place on the Canadian segment of the Alliance Pipeline System.

\section{NGTL EXTRACTION RIGHTS CONVENTION}

The NGTL System is the dominant natural gas transportation system in Alberta and currently incorporates roughly 23,500 kilometres of pipeline, gathering and transporting roughly two-thirds of the natural gas produced in Western Canada. ${ }^{27}$ Most of Alberta's ethane extraction, and a very significant portion of Alberta's $\mathrm{C}_{3}+$ extraction, occurs at straddle plants on the NGTL System, ${ }^{28}$ making it a very important piece of Alberta's NGL extraction industry.

In the context of NGL extraction, the NGTL System differs from the other Alberta Gas Systems in that the NGTL Tariff does not contain any express provisions addressing the disposition of NGL extraction rights by shippers, meaning that shippers inferentially retain their inherent rights as bailors (or equivalent) in that respect. However, because the NGTL terms of carriage have never stipulated how these extraction rights are to be allocated and

AltaGas Utilities Inc., Transportation Service Regulations for Rate 10 - Producer Transportation Service, online: AltaGas <http://www.altagasutilities.com/files/pdf/Decision\%202007-079\%20 (Addendum)\%20PTSR.pdf $>$.

23 Ibid. at para. 2.8.

24 See “Alliance Pipeline Extraction Agreement (Canadian Version),” ss. 2-3, online: Alliance Pipeline <http://www.alliance-pipeline.com/contentfiles/65_New_Shipper_Contracts_CDN_Extraction_ Agreement.pdf $>$.

The Aux Sable Story, online: Aux Sable <http://www.auxsable.com/story.html>.

Ibid.

TransCanada's Alberta System: A Profile, online: TransCanada <http://www.transcanada.com/gas_ transmission/alberta.html>.

Inquiry Decision, supra note 1 at 9. 
exercised, that is all currently dealt with by way of a "convention” that has evolved over the years (the Current NGTL Convention).

The development of the Current NGTL Convention commenced when the first straddle plants were built on the NGTL System in the early 1960s. At that time shippers on the NGTL System were comprised primarily of major natural gas aggregators such as TransCanada PipeLines Limited (TransCanada) and Alberta and Southern Gas Company, which held both receipt and corresponding delivery service on the NGTL System. The first straddle plants constructed on the NGTL System were located near Empress, on the eastern leg of the system, immediately upstream of the export delivery point at the Alberta/Saskatchewan border. Because these straddle plants were located at the tail-end of the system, it made practical sense to allocate extraction rights on the basis of delivery nominations being made at the delivery point immediately downstream of the plants. The shippers taking delivery of gas at that point were the logical choice to authorize processing of that gas immediately before delivery. And because shippers at that time held both receipt and delivery service, there was no material issue with respect to whether one class of shipper was being favoured over another. As a result, NGTL simply began to accommodate arrangements under which straddle plant operators would acquire extraction rights from shippers holding downstream delivery service and the Current NGTL Convention was born. ${ }^{29}$

The NECTF Report described the development of the Current NGTL Convention as follows:

The convention is rooted in the industry's history. When the original extraction plants were built, aggregators were the only Alberta export shippers on the NGTL System; they held both the receipt and delivery transportation. Since the extraction plants were physically located near export delivery points, administering extraction based on export nominations was operationally efficient. ${ }^{30}$

Following the deregulation of natural gas prices in 1985, the NGTL shipper base began to expand dramatically, and over the ensuing years NGTL began to offer new transportation options that resulted in greater diversity in holdings of receipt service and delivery service. 1993 NGTL introduced NOVA Inventory Transfer (NIT) service, which allowed receipt shippers to transfer their common stream rights within the NGTL System. This development meant that a shipper could elect to hold only receipt service, and sell all of its NGTL System gas (i.e. its common stream recovery rights) within the System. Correspondingly, a buyer of gas could elect to acquire only delivery service, and buy all of its NGTL System gas within the system, thereby avoiding the need to hold and pay for receipt service. Although this was a tremendous development from a gas marketing perspective, it clouded the picture with respect to the nature and extent of each shipper's interest in the NGTL common stream, and gave rise to questions with respect to whether the Current NGTL Convention continued to be fair and appropriate in the changed circumstances. Given that NIT transfers occur at some undefined notional point within the NGTL System, it is not clear whether the NIT transferor or the NIT transferee should be entitled to exercise common stream rights at any particular point within the system. Under the Current NGTL Convention it is the NIT transferee (i.e. 
the delivery service shipper) that is allocated all common stream NGL extraction rights, and this became an issue for many receipt weighted shippers, as well as the EUB.

In this respect, the EUB observed as follows in the Inquiry Decision:

The Board continues to hold the view ... that resource ownership should remain with the producer of the resource until the producer relinquishes ownership through a commercial contract. NGL are part of the natural gas resource produced from wells, and thus in the Board's view, the producers of natural gas have the right to the NGL entrained in the gas they produce until such time as they contract that entitlement to another party. Under the Current Convention, only an export delivery shipper has an entitlement to contract with respect to the extraction rights associated with gas being transported on the NGTL System.... Accordingly, producers/receipt shippers do not have an opportunity under the Current Convention to realize an incremental value for extraction rights or to separately contract for the disposition of their proportionate entitlement to the NGL components of the Common Stream.... The Board agrees that the Current Convention creates an inequity for producers/receipt shippers who do not wish to acquire export delivery service, but yet would like to receive value for the extraction rights associated with their proportionate share of the Common Stream. ${ }^{31}$

\section{GENESIS OF THE INQUIRY}

The regulatory history relating to NGL extraction issues on the NGTL System includes a series of EUB decisions which culminated in the Inquiry. EUB decisions predating the Inquiry raised questions surrounding NGL ownership and extraction rights that remained unresolved at the time the Inquiry was initiated.

\section{A. The GulF Strachan Decision}

In 1996 Gulf Canada Resources Limited (Gulf) applied to the EUB for an order allowing Gulf to cause natural gas to be diverted from the NGTL System to the Gulf operated Strachan gas plant (the Strachan Plant), for the purpose of enabling Gulf to extract NGLs from the diverted gas at the Strachan Plant. Following extraction processing, the diluted gas would be returned to the NGTL System, upstream of the Cochrane straddle plant. The quantity of gas that Gulf was seeking to divert and process was intended to be limited to that portion of the common stream to which Strachan Plant owners were entitled as a result of deliveries into the NGTL System upstream of the Strachan Plant.

In the EUB's decision in the matter, ${ }^{32}$ Gulf's proposed diversion initiative was characterized as a "side-streaming” project, as distinguished from a "co-streaming” project. Side-streaming involves the diversion of common carrier gas upstream of a straddle plant, the processing of that gas for NGLs extraction at an off-system field plant, and the return of the diluted gas back into the system at a point upstream of the straddle plant, such that the gas available for processing at the straddle plant is leaner than it otherwise would have been. Co-streaming also involves the diversion of common carrier gas upstream of a straddle plant 
and the processing of that gas for NGLs extraction at an off-system field plant, but provides for return of the diluted gas back into the system downstream of the straddle plant, such that the straddle plant has a lesser volume of gas available to process, but does not have to contend with a diluted gas stream. Both side-streaming and co-streaming can be expected to have an adverse impact on the downstream straddle plant, but each in a different way.

There were a number of issues examined by the EUB in the Gulf Strachan decision, but most relevant to the subject matter of the Inquiry was the EUB's conclusion relating to ownership of the common stream of natural gas (and associated NGLs) on the NGTL system: "The Board acknowledges that joint ownership, with its associated issues, exists among shippers in the NGTL common stream but maintains that individual owners should be afforded the right to reprocess their share of the stream provided this does not afford that producer an exclusive privilege."33

The EUB thereby confirmed that the shippers of natural gas on the NGTL System relinquish their rights to the specific natural gas (and associated NGLs) delivered at a receipt point in exchange for a proportionate share of the common stream. However, the EUB also recognized that each shipper of natural gas on the NGTL System should be entitled to process its share of the common stream, so long as other shippers are not adversely affected. In granting Gulf's application, the EUB allowed for the Strachan Plant to be permitted to remove specified volumes of NGLs from the common stream provided that ownership of such NGLs could be directly attributed to the Strachan Plant owners. ${ }^{34}$ In this respect, the EUB indicated that a producer/shipper that delivers natural gas to the NGTL System should be able to realize the economic benefits arising from the component hydrocarbons that it contributes to the common stream.

In order to allow Gulf to extract NGLs at the Strachan Plant with no adverse impact on other shippers, the EUB placed certain conditions on its approval of Gulf's side-streaming proposal. Gulf was required to implement, and fund, (1) a monitoring system that would track the specific volumes of natural gas that were side-streamed and (2) a component monitoring system that would ensure that only those NGLs that were delivered to the NGTL System by Strachan Plant owners were extracted from the common stream at the Strachan Plant. Furthermore, Gulf and the other Strachan Plant owners would be restricted from realizing any economic gains arising from the extraction of common stream NGLs at any straddle plant downstream of the Strachan Plant. This restriction was put in place by the EUB so that the Strachan Plant owners would not be able to "double dip"; that is, Gulf and its partners would not be able to reap the economic benefits of NGL extraction, once through extraction at the Strachan Plant and again through the granting of NGL extraction rights to a straddle plant operator. ${ }^{35}$ In the end, Gulf did not proceed with the Strachan Plant sidestreaming proposal.

In the Gulf Strachan decision, the EUB clearly enunciated its support of the view that producers/receipt shippers should be provided the right to extract and process their 
proportionate share of NGLs entrained in the common stream, and thereby realize the economic benefits of the NGL components they contribute to the NGTL System. The EUB further confirmed, however, that the rights of each shipper/producer to extract and process NGLs must be subject to (1) the limitation that the economic interests of other producers/shippers are not adversely affected, and (2) the requirement that the broader public interest be maintained. The endorsement of these principles in the Gulf Strachan decision helped set the stage for subsequent review and reconsideration of the Current NGTL Convention.

\section{B. THE SOLEX DECISION}

In 2003 Solex Gas Processing Corp. (Solex) applied to the EUB for approval of a sidestreaming scheme involving the diversion of NGTL System gas to the Harmattan-Elkton gas plant (the Harmattan Plant), upstream of the Cochrane straddle plant. ${ }^{36}$

In requesting that it be entitled to the same opportunity to extract NGLs as was afforded to the existing straddle plants, Solex submitted that:

when a producer put its gas on the NGTL system, it gave up ownership of the gas and its constituents in exchange for an entitlement to the energy value it represented.... [T]he producer therefore abandoned its NGL in return for transportation services and an energy entitlement.... The abandoned NGL could then be scavenged by anyone on the system with extraction capacity. ${ }^{37}$

In its decision in the matter the EUB reaffirmed its findings from the Gulf Strachan decision pertaining to the ownership of natural gas and entrained NGLs transported on the NGTL System:

The Board reaffirms that a producer with a share of the common stream has the right to reprocess its proportionate share of the common stream, subject to the public interest.

The Board continues to acknowledge, as it did in the Strachan decision, that joint ownership with its associated issues exists in the NGTL common stream. The Board understands that under common law and under the NGTL tariff, this means that once a producer/receipt shipper puts its gas on the NGTL system it no longer owns that particular gas. The Board agrees with ATCO that at that point the producer/shipper gives up any and all rights to that specific gas and acquires, in exchange, a share of the common stream. A producer/shipper's entitlement from that point on is limited to a right to reacquire its share of the common stream once it is severed or partitioned from the common stream. On the NGTL system, the severance or partition occurs when gas is delivered by NGTL to a customer at a delivery point. Therefore, the Board understands that all shippers together own the entire stream while the gas is contained within the NGTL facility. $^{38}$ a Licence for Pipelines Harmattan-Elkton Field (23 July 2003), EUB, online: EUB <http://www.ercb. ca/portal/server.pt/gateway/PTARGS_0_240_2570049_0_0_18/>. Solex Gas Processing Corp. - Application to Amend a Gas Processing Scheme for Natural Gas
Pipelines (27 January 2004), EUB Decision 2004-006 at 4, online: ERCB <http://www. ercb.ca/docs/documents/decisions/2004/2004-006.pdf> [Solex]. Ibid. at 8 . 
The EUB then went on to consider the Current NGTL Convention and whether it adequately recognized this right of ownership:

The Board is concerned that parties to the hearing expressed that the current convention creates some inequities among shippers on the NGTL system. For example, some producers that are also receipt shippers never get the full benefit of their NGL if they do not hold export delivery capacity. In addition, shippers with delivery capacity at the export points stand to benefit from NGL extraction without having to put any gas on the system.

The Board finds that the approval of the Solex application may affect the current straddle plant business practices for NGL extraction and may ultimately require changes to the current convention. In an effort to compete, Williams and other straddle plant owners may have to revert to receipt-point contracting. The Board believes that prior to formally considering any changes to the current convention, there ought to be a proper stakeholder consultation and assessment of the implications of any change on the viability of the straddle plant system, the proprietary rights of producers, and natural gas markets. ${ }^{39}$

In the Solex decision, although inequities and short comings related to the Current NGTL Convention were recognized, these were not explored in detail. The EUB denied Solex's application and in so doing noted several points of differentiation as compared to the Gulf Strachan decision; the Solex proposal involved the processing of much larger volumes of natural gas than was the case in the Gulf Strachan decision and Solex also proposed to process significant volumes of third-party natural gas at the Harmattan Plant. ${ }^{40}$ The EUB further recognized that, since the Gulf Strachan decision, new industry circumstances had led to an increased likelihood of additional side-streaming applications: ${ }^{41}$ there had been an increase in available capacity at field processing plants, and a new Alberta royalty structure encouraged natural gas producers to realize the value of the NGLs that they contributed to a regulated pipeline's common stream. ${ }^{42}$

In the view of the EUB a change in mindset was necessary before any other sidestreaming applications could be approved, ${ }^{43}$ and significant industry consultation was required in order to resolve the issues of NGL ownership and NGL extraction rights and to address the inequities existing under the Current NGTL Convention. In order to stimulate the desired industry consultation process, the EUB issued a direction to stakeholders:

\footnotetext{
$39 \quad$ Ibid. at $12-13$.

$40 \quad$ Ibid. at 8.

41 Ibid.
}

42 Solex applied to the Alberta Court of Appeal for leave to appeal the EUB's decision. After reviewing the decision of the EUB and the applicable administrative law standards of review, O'Leary J.A. concluded that "the applicants have not raised serious arguable issues of law or jurisdiction sufficient to justify granting leave to appeal the Decision the Court of Appeal”: Solex Gas Processing Corp. v. Alberta (Energy \& Utilities Board), 2004 ABCA 388, 361 A.R. 232 at para. 49.

43 Following the Solex decision, Taylor Processing Inc. (Taylor), which has acquired the Harmattan Plant from Solex, submitted an application to the EUB requesting authorization for the Harmattan Plant to costream natural gas. This application was suspended pending the results of the Inquiry and has since been re-opened by AltaGas Income Trust, which acquired Taylor. See Part IV.D, below. 
[the EUB] is concerned about the inequities, as presented at this hearing, in the current convention and would expect that this matter would be resolved through an industry process and the Board be advised by October 31, 2004. This industry process should be inclusive of affected parties, providing all constituents with a reasonable opportunity to advance their positions and concerns. The Board recognizes that there are a number of possible venues available to industry to initiate this review, but the Board believes that the preferred option is the collaborative process afforded to all NGTL shippers through the TTP committee. The Board requests that parties work with NGTL to initiate this review by April 1, 2004. If this issue has not been addressed through the TTP or otherwise, the Board may direct NGTL to consider this matter in its next tariff application. $^{44}$

\section{THE NECTF REPORT}

In response to the EUB's request for an "industry process" in the Solex decision, the NECTF was formed in June of $2004 .^{45}$ The objective of NECTF was to "create a balanced and unbiased report for the EUB regarding the Current Convention and any identified alternatives." ${ }^{46}$ Ultimately NECTF generated the NECTF Report and submitted it to the EUB on 28 September $2005 .^{47}$

Prior to the formation of NECTF, TransCanada Pipelines Limited's Customer Advisory Council (CAC) had met several times and described five perceived inequities existing under the Current NGTL Convention, as well as four proposed alternatives for dealing with those inequities. ${ }^{48}$ Along with an extensive review of the history and operation of the NGTL System and the associated development of the Current NGTL Convention, discussion of the five perceived inequities, as well as the list of proposed alternatives, which was eventually expanded to five, ultimately comprised a significant portion of the NECTF Report. The five perceived inequities were as follows: ${ }^{49}$

(1) Receipt Shippers Contributing Dry Gas to the NGTL System:

Receipt shippers, who also hold delivery capacity, that contribute natural gas with little or no NGL content to the NGTL system, are, through their entitlement to a proportionate share of the common stream, able to access, and capitalize on, the NGLs entrained in the NGTL System and have been contributed by other shippers.

Solex, supra note 37 at 24. The TTP committee refers to TransCanada Alberta System Tolls, Tariff \& Procedures Committee (now the Tolls, Tariff, Facilities \& Procedures Committee). See "Tolls, Tariff, Facilities \& Procedures Committee: Procedures," online: TransCanada <http://www.transcanada.com/ Alberta/industry_committee/tolls_tariff_facilities_procedures/TTFP_Procedures_Revised_ADOPTED_ OCT_13_04.pdf $>$.

For a listing of the members of NECTF, see NECTF Report, supra note 3 at 8.

46 TransCanada, Tolls, Tariff, Facilities \& Procedures Committee Resolution T2004-04 (28 September 2005), online: TransCanada <http://www.transcanada.com/Alberta/regulatory_info/active_rates_pdfs/ 2005_09_28_TTFP_Resolution_T2004_04_NGL_Extraction_Convention.pdf $>$. 
(2) Double Dipping:

Producer shippers, who also hold delivery capacity, that extract NGLs from their natural gas at field processing stations upstream of the NGTL system, are, through their entitlement to a proportionate share of the common stream, able to access and capitalize on the NGLs entrained in the NGTL System and have been contributed by other shippers. Producer shippers, who also hold delivery capacity, with production that enters the NGTL System downstream of extraction plants can obtain value for NGLs in the common stream, even though their gas cannot be physically processed by straddle plants on the NGTL System.

(3) Producers Without Export Delivery Service:

Producer shippers, who do not hold delivery capacity, cannot directly access NGLs that they have contributed to the NGTL common stream.

(4) Producer Rights to NGL:

Decisions of the EUB, in particular the Gulf Strachan decision and the Solex decision, have confirmed that the producer of natural gas has the rights to entrained NGLs until such time as rights to these components have been explicitly transferred to another party. In this respect, the Current NGTL Convention does not allow these rights to be exercised unless the shipper holds delivery capacity.

(5) Payment of Royalties by Producers:

Producers of natural gas are required to pay Provincial royalties on NGL production and may be unable to access the economic benefits of the NGLs that are contributed by the producer to the NGTL System unless the shipper holds delivery capacity.

Given the inequities described, the main issues identified by NECTF relating to the Current NGTL Convention surround the fact that, unless they hold delivery capacity downstream of a straddle plant, producers/receipt shippers of natural gas are unable to realize the economic benefits of the NGLs that are component parts of the gas they contributed to the common stream at the inlet point. Such a situation is counter to the stated views of the EUB found in both the Gulf Strachan decision and the Solex decision and is not in conformity with general principles of common law.

The five proposed alternatives to the Current NGTL Convention were as follows: ${ }^{.0}$

(a) Equalization:

The Equalization alternative described in the NECTF Report would mirror the existing equalization process used for crude oil and condensate delivered to 
pipelines in Alberta. In the case of natural gas delivered to NGTL, heat content would be used as the equalization factor. Equalization would require shippers of lean gas to transfer a portion of their revenues from the sale of that gas to shippers of natural gas richer in NGL content. The current commercial process for NGL extraction on the NGTL System would not be altered as between straddle plants and the holders of delivery service downstream of the extraction capacity. The inequality between shippers of rich gas versus lean gas would be addressed and there would be minimal impact on current industry practice.

(b) Single Value Bucket:

The Single Value Bucket alternative would continue to result in delivery shippers contracting with straddle plants for NGL extraction and would see the straddle plants aggregate all extraction premiums into a single "bucket” or account. Shippers would receive a share of the overall value of the "bucket" based on the heat value of the natural gas (including NGLs) that each shipper delivered to an NGTL pipeline inlet. Under this alternative, a share of NGL extraction value would be allocated to the owner of the NGLs at the time they were delivered to the NGTL System while requiring only limited administrative oversight.

(c) Receipt Contracting:

The Receipt Contracting alternative described by NECTF would transfer the NGL extraction entitlement, along with the associated value, from the delivery shipper to the receipt shipper. The receipt shippers would be allocated a proportionate share of the common stream and would be entitled to contract with straddle plant operators for NGL extraction. This alternative aligns NGL ownership and extraction rights more closely with the payor of Provincial NGL royalties in that the producers are assumed to either be receipt shippers themselves, or to have agreements with receipt shippers recognizing the value of NGLs. This alternative does not fully address the lean gas/rich gas inequality because receipt shippers or producers contributing dry gas (devoid of NGLs) would still be able to realize economic gains from the NGLs entrained in their proportionate share of the common stream.

(d) Producer Directed:

Under the Producer Directed alternative, ownership of NGLs entrained in the NGTL common stream, along with the associated extraction rights, would be represented by extraction rights credits (ERC). ERCs would be allocated at the receipt point onto the NGTL System and would be tracked back to the natural gas owner upstream of the receipt point. ERCs could be traded separately from the NIT natural gas market and would be owned by producers until such time as NGL ownership was directly transferred to an extraction plant. This alternative would maintain the flexibility and efficiency of the NIT market while allowing producers to benefit from the value of the NGLs that they have delivered into the NGTL System. 
(e) Regulated Business:

The Regulated Business alternative is intended to provide a balance between maintaining the viability of the extraction plant system and the rights of resource owners to capture the in-stream components of their NGLs in kind. Under this proposal, the straddle plants on the NGTL System would be regulated under the Gas Utilities $A c t^{51}$ on a cost-of-service basis, and would be entitled to extract NGLs from the common stream in kind. The straddle plants would be aggregated into a single composite plant, including costs and yields. Natural gas owners would be required to process their proportionate share of the common stream through the straddle plants, would be compensated for their share of NGLs that are extracted (NGL entitlements would be allocated in proportion to the components that each owner delivered to the NGTL inlet point) and would be responsible to contribute their proportionate share of the cost of NGL extraction service.

In a letter dated 24 July 2006, the EUB responded to the findings outlined in the NECTF Report and "reluctantly" accepted the report as satisfaction of the direction provided to industry participants in the Solex decision. ${ }^{52}$ Although the EUB acknowledged the time and effort that went into the preparation of the NECTF Report, as well as the difficulties that the task force faced in terms of reaching a consensus among stakeholders with varying economic interests, overall the EUB was not satisfied with the report. In particular, the EUB took issue with the fact that the parties involved in preparing the NECTF Report could not reach a consensus view as to the actual existence of inequities resulting from the Current NGTL Convention, and did not assess the value or costs associated with any perceived inequities. ${ }^{53}$

Given its general dissatisfaction with the NECTF Report, and rather than waiting for further applications relating to NGL extraction matters to be brought forward by individual industry particpants, the EUB considered it prudent to schedule a direct inquiry into the issue of NGL extraction in hopes of resolving the outstanding commercial and equitable issues.

\section{The INQUIRY PROCEEDINGS AND DECISION}

On 4 June 2007, the EUB published a notice initiating an inquiry into matters related to NGL extraction from the common natural gas stream transported through pipeline transmissions systems or processed by facilities that are regulated by the EUB. ${ }^{54}$ In this notice, the EUB stated that it was initiating the Inquiry because it felt that

there is a need for a timely and comprehensive re-examination of historical conventions and practices with respect to the extraction of NGLs on EUB regulated pipelines and facilities. The need for such a review is made further apparent in light of anticipated future developments including the use of EUB regulated pipelines to transport increased amounts of gas sourced outside of Alberta, development of sources of [coal

R.S.A. 2000, c. G-5.

Inquiry Decision, supra note 1 at Exhibit 001-08-06: Board Letter to Interested Parties in Response to NGL NECTF Report (24 July 2006).

Ibid.

Ibid. at Appendix 3 - Exhibit 001-01: Notice of Board Initiated Proceeding (4 June 2007). 
bed methane] and the growing market for gas within the Province. This Inquiry will consider these conventions and practices to determine if changes are required in the public interest. ${ }^{55}$

By letter dated 6 July 2007, ${ }^{56}$ following comments received from parties who expressed an intention to participate in the Inquiry, the EUB finalized the scope of the Inquiry and the list of issues to be canvassed. The EUB also outlined the anticipated outcomes for the Inquiry.

Given the issues and outcomes identified by the EUB, it was clear that the EUB would ultimately focus on three major issues. These three issues were noted in the Inquiry Decision as being:

- NGL extraction rights and whether or not the current extraction rights convention or tariff provisions should be changed;

- $\quad$ ongoing regulatory policy respecting lean gas streaming; and

- $\quad$ ongoing regulatory policy respecting co-streaming and side-streaming. ${ }^{57}$

\section{A. The Regulator}

Even from the first procedural schedule released as part of the Inquiry Notice, it was apparent that the Inquiry would likely continue beyond 1 January 2008, the date when the EUB was scheduled to split into two separate regulatory bodies, the AUC and the Energy Resources Conservation Board (ERCB). In a letter dated 24 January 2008, the EUB made it clear that notwithstanding the creation of two separate tribunals, the EUB would continue its jurisdiction over the Inquiry with panel members and staff from both the ERCB and AUC. In the end, Mr. Brad McManus, Q.C. (now with the ERCB) served as the Inquiry panel chair, with Ms. Carolyn Dahl Rees (now with the AUC) and Mr. Gerry DeSorcy (former chair of the pre-EUB Energy Resources Conservation Board between 1987 and 1993) being the other members.

The fact that the Inquiry continued beyond 1 January 2008 did cause the EUB to amend its anticipated outcomes for the Inquiry. In its 15 August 2008 Ruling Regarding Motion and Notice of Constitutional Law, the EUB wrote:

the Board has determined that it will make recommendations only with respect to matters dealt with in the Inquiry, rather than issue specific decisions or directions in relation to any such matters.

Although the division of the Board into two tribunals ... had been proposed at the time that the Inquiry commenced, the ultimate passage of legislation, the form that legislation might take and the timing of

Ibid. at Appendix 3 - Exhibit 001-01 at 2.

Ibid. at Appendix 4 - Exhibit 001-08: Inquiry into NGL Extraction Matters (6 July 2007).

Ibid. at 27. 
enactment were uncertain. The creation of the ERCB and the AUC as of January 1, 2008 clearly demonstrates the intention of the legislature to phase out any ongoing role for the Board. Accordingly, further proceedings or processes, including compliance filings that could result from directions of this Board would fall to these successor tribunals to consider. Although the Board remains able to issue decisions and directions as originally contemplated, from a practical perspective, the Board considers such measures in the circumstances to be inadvisable. Making recommendations to the applicable authority appears to be the most appropriate method of proceeding. ${ }^{58}$

\section{B. The Participants}

In its Notice, the EUB included a lengthy list of the types of parties that it hoped would participate in the Inquiry despite the fact that no cost claim or intervener funding process would apply. ${ }^{59}$ The EUB essentially issued an invitation to parties representing all affected business areas to participate in the Inquiry, including producers, straddle plant owners and operators, gas and liquids transmission pipeline operators, pipeline shippers, governments, industry groups, and parties involved in the petrochemical industry.

By the end of the Inquiry hearing, there were approximately 60 parties registered to participate $^{60}$ representing various aspects of the NGL business, just as the EUB had hoped. Notably however, several registered parties did not take an active role in the hearing process, instead choosing to submit position statements or taking an even more passive role by only monitoring the Hearing and receiving notices. As an example, Dow Chemical Canada Inc. (Dow), one of the two major ethane buyers in the Province, was a registered party but did not take an active role in the Inquiry. Similarly, AltaGas Utilities, one of the regulated gas pipeline distributors in the Province, did not participate in the hearing beyond registering as a party despite the fact that AltaGas Utilities was specifically identified by the EUB in its Final List of Issues. ${ }^{61}$

There were also concerns expressed regarding the lack of small gas producers participating in the Inquiry and whether purported benefits to producers that may develop from a change to the Current NGTL Convention could be realized by such small producers. The EUB though made it clear at the outset that because the process was EUB initiated, as opposed to a more traditional hearing resulting from a dispute between two or more parties, the EUB was relying upon voluntary participation of parties. ${ }^{62}$ The public inquiry process was, in the EUB's view, “the most appropriate mechanism to foster an open and inclusive process for interested parties to present and cross-examine evidence and for the EUB to fully understand related issues and address them." ${ }^{63}$ In short, the EUB was not prepared to compel participation in the Inquiry in the interests of developing a more fulsome record.

In the end, the number and diversity of participants still allowed the EUB to produce a decision that thoroughly reviewed the issues presented. Moreover, the EUB did not hesitate

Ibid. at Appendix 13 - Exhibit 001-42: Ruling Regarding Motion and Notice of Question of Constitutional Law (15 August 2008) at 9.

Ibid. at Appendix 3 - Exhibit 001-01 at 2.

Ibid. at Appendix 1.

Ibid. at Appendix 4 - Exhibit 001-08 at Attachment 3.

Ibid. at Appendix 3 - Exhibit 001-01 at 2.

Ibid. at 22. 
to issue recommendations that affected even those who did not actively participate in the Inquiry, such as AltaGas Utilities.

\section{THE INQUIRY EXPERT}

The EUB used its authority to appoint an independent expert (the Inquiry Expert) as a means of ensuring that the issues to be discussed would be thoroughly reviewed in the Inquiry. ${ }^{64}$ Notably, the EUB followed a distinctly different approach than that which it employed during the Gas over Bitumen (GOB) hearings when a group of EUB staff members were identified and separated to form the Staff Submission Group (SSG). ${ }^{65}$ While the SSG's overall mandate in the GOB hearings was arguably different than the Inquiry Expert in the Inquiry, the SSG was nevertheless intended to be a group responsible for completing its own technical review of parties' submissions, participating in cross-examination as required, and submitting final and reply argument, all with a view to ensuring that the EUB had a complete evidentiary record. ${ }^{66}$ The SSG was a prominent player in the Chard-Leismer GOB hearings, a matter involving 27 applications heard concurrently for either the shut-in or production of gas in Alberta's Athabasca oil sands area. ${ }^{67}$ Although the SSG was intended to perform its function at "arm's-length" from the EUB, not surprisingly, the formation and role played by the SSG in the GOB hearings led to criticism by some parties that there was a reasonable apprehension of bias, arguing that the SSG was not truly "independent" of the EUB. ${ }^{68}$

In the Inquiry, the EUB first introduced the concept of the Inquiry Expert in its letter of 6 July 2007. There, the EUB stated:

In preparing the initial scope for the Inquiry it became evident that the assistance of a recognized industry consulting firm with expertise in matters before the Inquiry, independent of all Parties and the Board, would be of assistance when considering the various issues to be examined by the Inquiry. The Board has engaged Ziff Energy Group as the Inquiry Expert. The Inquiry Expert will have the responsibilities outlined below.

1. The Inquiry Expert will consider the submissions from Parties to determine which areas require clarification and to identify any informational gaps in the evidence before the Board. The Inquiry Expert will submit information requests to try and achieve clarification and to fill in information gaps. Where it is unable to obtain missing information from parties it will attempt to provide the necessary information in a report (Report) to be filed with the Inquiry. Missing information to be supplied by the Inquiry Expert will primarily be with respect to providing data and forecasting information as well as completing background information from Alberta and other relevant jurisdictions.

Ibid. at Appendix 4 - Exhibit 001-08 at 5.

Letter from William Kennedy to Michael Bruni (13 March 2001), online: ERCB <http://www.ercb.ca/ docs/new/announce/letter_staff_subm_2001-03-13.pdf>.

Ibid.

Chard Area and Leismer Field Athabasca Oil Sands Area Applications for the Production and Shut-in of Gas (March 2003), EUB Decision 2003-023, online: ERCB <http://www.ercb.ca/docs/documents/ decisions/2003/2003-023.pdf>. Ibid. at 100 . 
2. The Inquiry Expert will conduct an analysis of the evidence of each Party and where the evidence is in significant conflict, the Inquiry Expert will comment in the Report on the points of conflict and highlight the strengths and weaknesses of the positions of the respective Parties.

3. The Inquiry Expert may also identify and assess in the Report one or more possible alternative approaches (or modifications to proposals put forward by Parties) to the matters before the Inquiry. The Inquiry Expert will advance an alternative approach(s) if it is of the opinion that such an alternative approach(s) would likely align with the overall Alberta public interest to a greater extent than any of the approaches suggested by the Parties. The Report will also assess the benefits, limitations and market impacts of any suggested alternative approach(s).

Dealings between the Board and the Inquiry Expert will be limited to administrative and financial matters. Neither the Board nor Board staff will have contact with the Inquiry Expert or review any drafts of the Report. $^{69}$

As indicated, the Inquiry Expert's Report was released to the EUB and the Inquiry participants at the same time. Also, the Inquiry Expert was subject to questioning by EUB staff and EUB members, just as any other party providing evidence during the Inquiry, further highlighting the “arm's-length” relationship between the EUB and the Inquiry Expert. The Inquiry Expert did not cross-examine any parties, nor did it submit any final argument. ${ }^{70}$ In this respect, the Inquiry Expert truly functioned independently of the EUB and Inquiry participants. While the views expressed by the Inquiry Expert clearly resonated with some parties to the Inquiry more so than others, unlike the GOB proceedings, no parties seriously or publicly challenged the independence and involvement of the Inquiry Expert.

\section{The Straddle Plant Operators}

Perhaps one of the more interesting aspects of the Inquiry was the coalition that formed amongst the straddle plant owners and operators participating in the Hearing, as well as changes to the coalition that resulted from events external to the Inquiry process.

At the outset of the Inquiry, AltaGas Ltd., ATCO Midstream, BP Canada Energy Co. (BP), Inter Pipeline Fund (IPF), Provident Energy Ltd. (Provident), and Spectra Energy Empress L.P. (Spectra) banded together to form the Straddle Plant Group. ${ }^{71}$ Then, on 10 January 2008, AltaGas Income Trust announced that it had successfully completed the acquisition of Taylor NGL Limited Partnership (Taylor), ${ }^{72}$ an organization that at the time was proposing to develop a co-streaming project which, if implemented, would compete with IPF's straddle plant facility located near Cochrane on the Western Leg of the NGTL System. ${ }^{73}$ As the Straddle Plant Group was expressing general opposition to the development

Inquiry Decision, supra note 1 at Appendix 4 - Exhibit 001-08 at 5.

Ibid. at 25.

Ibid. at 113 .

AltaGas Income Trust, News Release, “AltaGas Income Trust Announces Successful Offer for Taylor NGL Limited Partnership” (8 January 2008), online: AltaGas <http://cnrp.marketwire.com/client/ altagas/n/release.jsp?actionFor=808572\&releaseSeq=35\&year=2008>.

AltaGas Income Trust, through its indirect, wholly-owned Taylor Processing Inc. entity, submitted its application for the Harmattan Co-Stream Project to the ERCB on 23 April 2009. See AltaGas Income Trust, News Release, “AltaGas Submits Harmattan Co-Stream Application to Regulators” (23 April 2009), online: AltaGas <http://cnrp.marketwire.com/client/altagas/n/release.jsp?actionFor=979011\& 
of co-stream facilities, AltaGas Ltd. withdrew from the Straddle Plant Group on 25 January 2008, thus highlighting during the Inquiry process the commercial interests of its members.

The membership of the Straddle Plant Group was reduced again when Provident withdrew from it on 3 July 2008. ${ }^{74}$ Provident's withdrawal was precipitated by the 17 June 2008 application of TransCanada ${ }^{75}$ for a Certificate of Public Convenience and Necessity from the NEB (the TransCanada Application) ${ }^{76}$ respecting jurisdiction over the NGTL System (referred to in the application as the TransCanada Alberta System). In its cover letter to the NEB, TransCanada wrote:

\begin{abstract}
TransCanada makes this Application to effect recognition that the TransCanada Alberta System is by law properly within Canadian federal jurisdiction and subject to regulation by the Board as part of a single federal undertaking. The requested approvals are required for the operation of the TransCanada Alberta System under NEB regulation. $^{77}$
\end{abstract}

TransCanada's filing caused the EUB to consider what impact, if any, the TransCanada Application had on the Inquiry. The EUB adjourned the Inquiry hearing in order to hear submissions from parties on 20 June $2008,{ }^{78}$ which lead to the EUB's decision dated 21 June 2008 concluding that it had the jurisdiction to continue with the Inquiry insofar as it related to the NGTL System and should proceed with the Inquiry without amending its scope or objectives. ${ }^{79}$ In response in part to submissions made by members of the Straddle Plant Group, arguing that their pre-filed evidence may have been different if the TransCanada Application had been filed earlier, the EUB provided parties the option of filing supplemental submissions. $^{80}$

The EUB's decision to continue the Inquiry following the filing of the TransCanada Application had several effects. First, Provident asserted that many of the issues addressed in the evidence of most parties, including the Straddle Plant Group, were beyond the jurisdiction of the EUB and as such, Provident held that "it would be inconsistent for it to present a witness in support of SPG evidence." ${ }^{\text {81 }}$ Provident withdrew from the Straddle Plant Group and the remaining members of the Straddle Plant Group were then collectively referred to as the "Group." 82 Second, some of the parties amended evidence that had already been attested to and cross-examined, and other parties deciding not to seat a witness panel

releaseSeq $=22 \&$ year $=2009>$.

Inquiry Decision, supra note 1 at 128.

Ibid. at 133 .

TransCanada Pipelines Limited ("TransCanada”) Application for Certificate of Public Convenience and Necessity and Related Approvals TransCanada Alberta System (17 June 2008), Application A1F6R0 (NEB), online: NEB <https://www.neb-one.gc.ca/ll-eng/Livelink.exe/fetch/2000/90464/ 90550/90715/518313/518500/524288/518486/B-1A_Application_for_Certificate_of_Public Convenience_and_Necessity_and_Related_Approvals_-_Alberta_System_(A1F6R0).pdf?nodeid= $518487 \&$ vernum $=0>$.

77 Ibid.

78 Inquiry Decision, supra note 1 at Appendix 12 - Exhibit 053-63: Board Procedural Ruling Regarding Impact of the Application by TransCanada Pipelines Limited to the National Energy Board (21 June 2008).

79 Ibid. at Appendix 12 - Exhibit 053-63 at 2.

Ibid.

Ibid. at 133.

The Group is referred to in the Inquiry Decision, ibid. at 116, as the Amended SPG. 
to support their pre-filed evidence. ${ }^{83}$ The Group, as well as Provident and IPF in their own right decided to withdraw portions of their pre-filed evidence. ${ }^{84}$ The withdrawn pre-filed evidence generally related to matters that, in their respective opinions, would more appropriately be considered by the NEB rather than a Provincial regulator, and included topics such as NGTL's tolls and tariffs as well as matters relating to NGTL facilities. This forced the EUB to consider what weight, if any, should be assigned to this "Unsupported and Unsponsored Evidence." ${ }^{85}$

\section{E. THE NGTL CONVENTION ISSUE}

\section{A CHANGE TO THE CURRENT NGTL CONVENTION?}

Although the NECTF Report identified several different alternatives to the Current NGTL Convention, most of the discussion during the Inquiry hearing centred on the primary conceptual issue of whether to maintain the existing delivery point convention or to adopt a receipt point convention along the lines of the NEXT Model.

Parties who supported maintaining the Current NGTL Convention included those operating border straddle plants and parties who hold only export delivery service on the NGTL System. ${ }^{86}$ The Group indicated a preference for maintaining the status quo and negotiating with export delivery shippers for NGL extraction rights, as opposed to having to deal with a potentially larger number of receipt shippers or gas producers. ${ }^{87}$ In particular, the Group was concerned about receiving assurances regarding title to gas, arguing that straddle plants must take title to the gas from parties who cause it to be delivered to the straddle plants for extraction and who are able to assure legal title to that gas at the point where it is severed from the NGTL common stream. ${ }^{88}$ Further, straddle plant operators were concerned about the effect of imposing new rules and regulations on an extraction industry already facing many challenges and uncertainty. ${ }^{89}$

The Western Export Group and Tenaska Marketing Ventures/Tenaska Marketing Canada (collectively WEG/Tenaska) and Pembina Pipeline Corporation (Pembina) took issue with the Perceived Inequities identified in the NECTF Report, arguing that they did not, in fact, exist, or did not exist to the degree to which they were described. ${ }^{90}$ Pembina argued that any

\section{Ibid. at 128.}

Ibid.

For a full discussion of the weight given to Unsupported Evidence before the Inquiry generally, please see the Inquiry Decision, ibid. at 127. With regards to Unsupported and Unsponsored Evidence, that which was already the subject of cross-examination was viewed by the EUB as being the same as any other evidence that was the subject of cross-examination despite the fact that it was no longer supported by the participants that sponsored that expert evidence. The participants who sponsored that evidence asserted that the evidence remained accurate and would have been relied upon but for the filing of the TransCanada Application. For Unsuppported and Unsponsored Evidence that was not the subject of cross-examination, the EUB determined that the evidence was still relevant. Because the original party sponsoring the evidence confirmed that the evidence remained accurate and the evidence had been tested to some degree through information requests, the EUB considered it appropriate to give such evidence greater weight than Supported but Unsponsored Evidence, but less weight than evidence that was subject to cross-examination during the hearing.

Inquiry Decision, ibid. at 38.

Ibid.

Ibid.

Ibid.

Ibid. at 38-39. 
inequity arising from the Current NGTL Convention was restricted only to those producers and receipt shippers who do not also hold delivery services on NGTL. ${ }^{91}$ Similarly, WEG/Tenaska argued that uncertainties introduced by a change to the Current NGTL Convention must be weighed against the degree to which any inequity may exist and the "significant and ongoing contribution of FT-D [Firm Transportation — Delivery] shippers to the public interest." ${ }^{22}$ Moreover, WEG/Tenaska pointed to the fact that producers already have three other means by which to obtain value for their NGLs: field extraction, negotiation for NGL value in NIT prices, or taking FT-D service directly. ${ }^{93}$ In contrast, FT-D shippers alone would lose the value of their extraction rights without gaining anything in return. ${ }^{94}$

Parties advocating a change to the Current NGTL Convention were primarily producers, who argued that it was unfair to make producers hold export delivery service in order to realize the value of the NGLs in their gas. ${ }^{95}$ Producers generally disputed the argument that they are able to obtain market value for entrained NGL components through NIT prices, as NIT pricing only reflects the value of NGLs on the basis of natural gas energy or heating value. ${ }^{96}$ In the view of EnCana Corporation (EnCana), a change to a receipt point approach would create the significant benefit of allowing producers to negotiate with any of the straddle plants to obtain fair value for their NGLs without the need to hold export delivery service. $^{97}$

Moreover, as ConocoPhillips Canada Limited (ConocoPhillips) asserted, the EUB previously established that the right of resource ownership should be with the producer of that resource until relinquished by commercial contract and the Current NGTL Convention was inconsistent with that ruling. ${ }^{98}$

Other producers such as Shell Canada Limited (Shell) and Imperial Oil Resources and ExxonMobil Canada Energy (Imperial/EMC) suggested that a change to a receipt point extraction convention would help attract gas from Alaska or Northern Canada. ${ }^{99}$ This position was also advocated by the State of Alaska, which stated in its opening statement:

Like any royalty owner or producer, it wants a fair value for the NGLs entrained in the gas. The State believes the perceived inequities identified in the NGL extraction convention task force September 2005 report, the NECTF report, are real, and that the current NGL extraction convention would prevent the State of Alaska and Alaska gas producers from realizing fair value for NGLs. ${ }^{100}$

NOVA Chemicals, interested in securing a long-term supply of ethane, also supported initiatives that would encourage use of Alberta gas transportation and NGL infrastructure,

Ibid. at 38.

Ibid.

Ibid. at 39.

Ibid.

Ibid.

Ibid.

Ibid.

Ibid. at 40.

Ibid.

Inquiry Decision, ibid. (Transcript of Inquiry Hearing, Volume 10 at 1009-10), cited in ibid. at 72 [Inquiry Transcript]. 
noting that producers stand to benefit from lower tolls and ethane buyers would enjoy greater ethane supplies if Northern Gas was attracted to NGTL. ${ }^{101}$

As described above, the positions of the parties could be simply characterized as "antichange,” advocated generally by the Group, Provident, IPF, WEG/Tenaska, and Pembina, and "pro-change," advocated generally by producers, industry associations, governments, and Nova Chemicals.

\section{THE NEXT MODEL}

For its part, NGTL advocated a change to a receipt point allocation system and further submitted the NEXT Model for consideration as a viable receipt point convention alternative. ${ }^{102}$ The NEXT Model allocates extraction rights to receipt shippers based on their relative contributions of NGLs into the NGTL System, measured through a value based weighting of individual NGL components. ${ }^{103}$ In NGTL's submission, the NEXT Model would resolve the inequities associated with the Current NGTL Convention as producers would be relieved of the onerous obligation of holding FT-D service in order to obtain value for their NGLs. ${ }^{104}$ In addition, a change to a receipt point convention would have the added benefit of attracting additional gas supply, particularly gas from Alaska and Northern Canada, to the NGTL System. ${ }^{105}$

NGTL also asserted that "under the NEXT Model, the day-to-day mechanics of extraction rights sales would remain virtually the same as they are today at the Empress/McNeill export point" ${ }^{\text {106 }}$ and could be administered without incurring any additional operating costs. ${ }^{107}$ The NEXT Model would have the added benefit of creating a situation where extraction rights are not tied to specific straddle plants or delivery points. ${ }^{108}$ This would provide buyers and sellers of extraction rights with additional flexibility which, in turn, may lead to the development of a transparent and liquid extraction rights market. ${ }^{109}$

For many of the same reasons cited above in relation to whether a change to a receipt point convention was warranted, producers were generally supportive of the NEXT Model. It was described as being practical, fair, and efficient. ${ }^{110}$ It was also recognized as addressing several of the inequities associated with the Current NGTL Convention, and perhaps most importantly, providing appropriate economic signals to resource owners, thus leading to efficient utilization of the existing infrastructure in Alberta. ${ }^{111}$

Inquiry Decision, ibid. at 42.

Ibid. at 43-49.

Ibid. at 44.

Ibid. at 49.

Ibid.

Ibid. at 46.

Ibid. at 47.

Ibid. at 46.

Ibid.

Ibid. at 50-53.

Ibid. at 51. 
The Group, WEG/Tenaska, and Pembina opposed the NEXT Model. ${ }^{112}$ In addition to referring to the same arguments cited in opposition to a move away from the Current NGTL Convention, the Group voiced concern over potential impacts on its operations, arguing that implementation of the NEXT Model and a change to receipt point contracting would impose significant additional costs in the order of hundreds of millions of dollars. ${ }^{113}$ Straddle plants are already working in a challenging environment with less gas production in Alberta and increased intra-Provincial demand, meaning that less gas is available to the straddle plants for extraction. ${ }^{114}$ WEG/Tenaska similarly expressed concerns over changes to existing commercial regimes, arguing that the NEXT Model "would transfer benefits away from delivery shippers, without compensation." 115 Standard gas purchase contracts would have to be revisited, thus disrupting long-standing commercial arrangements. ${ }^{116}$ This would not be consistent with the EUB's historical reluctance to interfere in commercial arrangements negotiated by parties. ${ }^{117}$

\section{OTHER PROPOSED MODELS}

The only parties to advocate methodologies different from those identified in the NECTF Report were Imperial/EMC and Shell. Shell initially proposed a receipt point convention using just the heating value of gas at receipt points as a basis for allocating extraction rights. ${ }^{118}$ Shell ultimately abandoned its proposal in favour of the NEXT Model, ${ }^{119}$ thus leaving Imperial/EMC's Comprehensive Component Metering Model (CCM Model) ${ }^{120}$ as being the only real alternative that had to be considered by the EUB.

The CCM Model proposed measuring NGL components at each receipt point and allocating to the receipt shipper the right to recover a corresponding quantity of each such NGL component from the common stream. ${ }^{121}$ The principal difference between the CCM Model and the NEXT Model is that the NEXT Model provides receipt shippers with a single percentage interest in all NGLs in the common stream, while the CCM Model would provide receipt shippers with different percentage interests in the individual NGL components (i.e., ethan, propane, butane, and pentanes plus) in the common stream. ${ }^{122}$ Imperial/EMC described the CCM Model as being "NEXT-plus"123 in that it builds on the NEXT Model by providing specific component tracking, but acknowledged that more work on the CCM Model would be required. As such, Imperial/EMC was not able to provide an accurate cost estimate for the implementation of the CCM Model. ${ }^{124}$

Ibid. at 53-61.

Ibid. at 55.

Ibid. at 56.

Ibid. at 53.

Ibid.

Ibid. at 54.

Ibid. at 68.

Ibid.

Ibid. at 62-68.

Ibid. at 63.

Ibid. at 63-64.

Inquiry Transcript, supra note 100, Volume 19 at 2607, cited in ibid. at 63.

Inquiry Decision, ibid. at 66. 
Imperial/EMC also argued that implementation of the CCM Model would allow producers to take their liquids in kind at a reasonable fee at any of the straddle plant outlets, providing them with even more flexibility in the marketplace. ${ }^{125}$

Generally speaking, Imperial/EMC's CCM Model did not receive widespread support from other producers or Inquiry participants because it lacked detail and parties were not able to assess precisely how the CCM Model would work and how much it would cost to implement. $^{126}$

\section{THE EUB's CONCLUSIONS}

The EUB confirmed its view that resource ownership remains with the producer of the resource until the producer relinquishes ownership through commercial contract, and this includes NGLs entrained in gas. ${ }^{127}$ The EUB accepted that the value of entrained NGLs is not reflected in NIT prices, or that any value given is negligible, ${ }^{128}$ and therefore the Current NGTL Convention "creates an inequity for producers/receipt shippers who do not wish to acquire export delivery service,” but would still like to receive value for the NGLs in the gas they deliver into the NGTL System. ${ }^{129}$ In the EUB's view, a change to receipt point contracting could "provide all parties with more equitable market signals by providing producers and receipt shippers with the opportunity to negotiate separately for the value of their extraction rights which should encourage the development of a competitive, transparent extraction rights market."130

The EUB further accepted that changing the Current NGTL Convention to a receipt based extraction rights allocation convention may increase the likelihood of gas from Alaska and Northern Canada being attracted to the NGTL System, which would increase utilization of Alberta's gas transmission and NGL extraction infrastructure. ${ }^{131}$ The EUB noted, though, that attracting Northern gas to Alberta did not constitute a strong enough reason by itself to change the Current NGTL Convention. ${ }^{132}$

Ultimately, the EUB accepted that a change to a receipt point convention would not result in substantial upheaval to the ongoing operation of the NGTL System, or to NIT market liquidity. ${ }^{133}$ Similarly, a change to a receipt point convention would not create uncertainty or damage the longevity of the straddle plant system as long as a reasonable transition period was incorporated. ${ }^{134}$

In short, the EUB felt that changing the Current NGTL Convention to a receipt based extraction rights allocation convention was warranted.

Ibid. at 65 .

Ibid. at 67-68.

Ibid. at 71.

Ibid. at 72 .

Ibid.

Ibid. at 80.

Ibid.

Ibid. at 74.

Ibid. at 81 .

Ibid. at 80 . 
With respect to the NEXT Model, the EUB accepted that it was well-developed and could be implemented in a reasonable time period without significant additional costs. ${ }^{135}$ More importantly, the NEXT Model seemed to resolve most of the Perceived Inequities outlined in the NECTF Report, except for the possible "double dipping," which may occur when "gas that is delivered to NGTL downstream of extraction facilities or alternatively, does not access extraction facilities, would still receive extraction rights corresponding to the NGL content of the gas that is delivered to the Common Stream."136 The EUB concluded that this inequity was not material enough to justify adding complexity and cost to the NEXT Model. The NEXT Model presented the best opportunity for the development of a broad based extraction rights market. ${ }^{137}$

While the EUB recognized that Imperial/EMC's CCM Model offered certain benefits, the lack of detail surrounding the CCM Model made it difficult to implement within a reasonable amount of time. ${ }^{138}$ The EUB noted that Imperial/EMC could pursue the CCM Model at a later date if it considered that system enhancements were still required. ${ }^{139}$

\section{TRANSITION-RELATED RECOMMENDATIONS}

The EUB recommended that the NEXT Model be implemented on the NGTL System within three years of the Inquiry Decision without any compensation being paid to the straddle plant operators or export delivery shippers. ${ }^{140}$ The EUB wrote:

Prior to filing an application, the Board recommends that NGTL discuss the following matters with its stakeholders with a view to streamlining subsequent regulatory consideration:

- $\quad$ amendments to the NEXT Model to take into consideration the findings of the Board;

- $\quad$ enhancements to the NEXT Model, including measures to facilitate the development of an extraction rights market and to provide for the ability to take-in-kind;

- $\quad$ implementation procedures;

- $\quad$ tariff amendments; and

- $\quad$ regulatory application specifics. ${ }^{141}$

The EUB also recommended that NGTL take immediate steps to encourage the development of a competitive, transparent market where producers and receipt shippers could negotiate the value of their extraction rights. In doing so, NGTL was encouraged to engage in consultation with all relevant stakeholders. ${ }^{142}$ 
Finally, the Board recommended that NGTL conduct a confidential survey of stakeholders in the extraction rights market two years after implementation of the NEXT Model to determine whether a competitive, transparent market has developed with a view to making necessary adjustments with "the appropriate regulator(s)."143

\section{APPliCABILITy TO OTHER REgUlated PiPELINES}

Although little if anything was said during the course of the Inquiry regarding the ATCO Pipelines and AltaGas Systems, the EUB noted that their respective tariffs act as a contract to take entitlement to NGLs away from producers/receipt shippers. ${ }^{144}$ The EUB was of the view that producers/receipt shippers should have an equal ability to realize the value of their extraction rights, regardless of which rate regulated pipeline provides transmission service. ${ }^{145}$ Therefore, with respect to ATCO Pipelines, the EUB recommended that it discuss its current extraction tariff with its customers and "make application for regulatory approval of any amendments which may result from those discussions." recommendation to AltaGas Utilities, applicable only if extraction facilities become available on the AltaGas Utilities System or through interconnects with other pipeline systems. ${ }^{147}$

\section{THE LEAN GAS StREAMING IsSUE}

Lean gas streaming "involves the separate physical routing of gas that is lean in NGL content directly to consumption markets and away from common stream flow paths directed past NGL extraction facilities." 148 An obvious example of where lean gas streaming would be suitable is in the context of coal bed methane, which has virtually no NGL content and is generally produced from a localized geographical area. ${ }^{149}$

Generally speaking, all parties who expressed a view on the lean gas streaming issue were in favour of the concept, as long as it could be done economically and without disrupting the flow of NGLs to extraction facilities. ${ }^{150}$ NGTL recommended that lean gas streaming issues first be addressed within industry committees, such as within its Tolls, Tariff, Facilities \& Procedures Committee (the TTFP). ${ }^{151}$ NOVA Chemicals, however, argued that some outside of the TTFP consultation may be affected by lean gas streaming issues. ${ }^{152}$ NOVA Chemicals further suggested that where new facilities are proposed on NGTL, a NGL impact assessment be required to assess, among other things, the impact of new facilities on NGL availability to the straddle plants. ${ }^{153}$ Provident and IPF also suggested that a NGL impact assessment of all major natural gas facility projects that might have an impact on the straddle plant industry ought to be required of project proponents. ${ }^{154}$

$\begin{array}{ll}143 & \text { Ibid. } \\ 144 & \text { Ibid. at } 72 . \\ 145 & \text { Ibid. } \\ 146 & \text { Ibid. at } 87 . \\ 147 & \text { Ibid. } \\ 148 & \text { Ibid. at 88. } \\ 149 & \text { Ibid. } \\ 150 & \text { Ibid. at 88-93. } \\ 151 & \text { Ibid. at 89. } \\ 152 & \text { Ibid. } \\ 153 & \text { Ibid. } \\ 154 & \text { Ibid. at 60. }\end{array}$


The only party who expressed opposition to lean gas streaming was Talisman Energy Inc., who understood that lean gas streaming "would target specific supply to specific markets, thereby undermining the benefits inherent in NGTL's common stream.”155 The EUB concluded that

notionally, lean gas streaming has merit when the loss of NGL can be avoided, but considers caution must be exercised particularly with respect to the total cost of such projects, who pays for these costs, the socioeconomic impact of a project (including the construction of duplicative facilities), and the potential impacts to the competitive position of gas sourced from the WCSB. ${ }^{156}$

Costs and benefits of lean gas streaming associated with applications for facility modifications or additions should be assessed on a case-by-case basis, in the context of ensuring that the project is in the overall public interest. ${ }^{157}$ The EUB was not prepared to require mandatory NGL assessments for all major facility proposals that could impact NGL extraction in the Province. The need for such an assessment would have to depend on the specific circumstances of each application.

The EUB agreed that further discussion regarding lean gas streaming on the NGTL System be held in an industry collaborative process facilitated through the TTFP, with invitations to all potentially impacted parties who may not otherwise be involved in TTFP discussions. ${ }^{158}$ Following such discussions, a report with guidelines, criteria, and implementation recommendations should be issued by 1 April 2010 and provided to the regulator for approval.

ATCO Pipelines and AltaGas Utilities were encouraged to consider an approach similar to that developed by the TTFP at such time as lean gas streaming opportunities develop in the future. ${ }^{159}$

\section{CO-STREAMING AND SIDE-STREAMING}

As discussed above, side-streaming occurs when an under-utilized upstream gas processing facility gains access to the common stream to extract NGLs and then re-injects lean residue gas back into the common stream upstream of an existing straddle plant. In the case of co-streaming, the lean residue gas is re-injected downstream of the straddle plant.

Most Inquiry participants favoured the EUB considering side-streaming and co-streaming proposals on a case-by-case basis, and argued that competition for existing straddle plant operations should be encouraged. Parties such as Taylor argued that prior EUB decisions, such as the Gulf Strachan decision and the Solex decision, along with EUB Directive 056, ${ }^{160}$

Inquiry Decision, ibid. (Talisman Energy Written Argument, September 5, 2008, at 2), cited in ibid. at 92.

Inquiry Decision, ibid. at 93.

Ibid. at 94.

Ibid. at 95.

Ibid.

Alberta Energy Utilities Board, Directive 056: Energy Development Applications and Schedules (Calgary: Energy and Utilities Board, 2005). 
already provide sufficient direction to potential applicants regarding matters to be included in facility applications. ${ }^{161}$

In contrast, straddle plant operators advocated the adoption of explicit criteria outlining what should be included in facility applications being put before the EUB and argued that the extraction industry is already highly competitive. ${ }^{162}$ Additional extraction facilities would be duplicative and inefficient, with little competitive benefits or incremental production of NGL. ${ }^{163}$ Straddle plant operators warned the EUB to be wary of plant operators preferring to profit from processing the common stream rather than raw gas. ${ }^{164}$

The Inquiry Expert indicated in its Report that it was not supportive of side-streaming due to the negative impact of reduced NGL content to downstream straddle plants, but suggested that case-by-case analysis of co-streaming applications would be appropriate. ${ }^{165}$ The Inquiry Expert identified a number of factors that could be addressed by facility applicants, such as the impact on Alberta NGL reserve recovery and production, and the impact on Alberta straddle plants and the petrochemical industry. ${ }^{166}$

The Board noted the position of the straddle plants that the extraction industry is already competitive in Alberta, but was not prepared to recommend a prohibition against costreaming or side-streaming developments. ${ }^{167}$ The EUB accepted that "there is likely limited economic potential for proliferation of co-streaming and side-streaming as evidenced by the very few applications of this type that have been filed to date." 168 The EUB further accepted that individual facility applications should be assessed on a case-by-case basis having regard for NGL recovery implications, potential effects on other facilities, and other elements of the public interest criteria. ${ }^{169}$ While the EUB did not consider it appropriate to set out a prescriptive list of criteria to be met by facility applicants, the EUB did outline general factors to be addressed in future co-streaming or side-streaming applications, being:

- " “the availability of existing unused processing capacity at the straddle plants";

- “availability of processing capacity for raw gas production”;

- “resource conservation and effective utilization of resources”;

- " cthe impact on the existing straddle plant system";

- “unnecessary proliferation of facilities”;

- “real meaningful competition”; and

Inquiry Decision, supra note 1 at 99.

Ibid. at 101.

Ibid. at 102 .

Ibid.

Ibid. at 103 .

Inquiry Decision, ibid. at 103-104 (Exhibit 049-05-01, Ziff Energy Inquiry Expert Submission Part 2, Section 8.2.9, page 8-12).

Inquiry Decision, ibid. at 104.

Ibid.

Ibid. at 105. 
• "support from the industry."”170

\section{THE NGTL JURISDICTION DECISION}

On 26 February 2009, just three weeks after the release of the Inquiry Decision, the NEB released the NGTL Jurisdiction Decision. ${ }^{171}$ The NEB granted TransCanada's application for an order recognizing that the NGTL System is under federal jurisdiction. ${ }^{172}$ The NEB decision emphasized that the NGTL System is part of TransCanada's extensive pipeline system operating throughout Canada. ${ }^{173}$ The NEB decided to issue a Certificate of Public Convenience and Necessity to allow the NGTL System to operate under the National Energy Board Act ${ }^{174}$ and the NEB's jurisdiction over the NGTL System became effective on 29 April 2009. ${ }^{175}$

Given the change in jurisdiction over the NGTL System, the question that arises is, what regard will the NEB have for the Inquiry Decision insofar as a change to the Current NGTL Convention and transition to the NEXT Model is concerned?

Practically speaking, in the short term, there is likely to be little impact on NGTL's plans to continue stakeholder consultation in the areas outlined by the EUB, specifically, any amendments or enhancements to the NEXT Model to take into consideration findings of the EUB, as well as implementation procedures, tariff amendments, and regulatory application specifics. Although merely a recommendation, NGTL arguably has just under three years to "tweak" the NEXT Model and bring forward an application to the NEB for implementation by 4 February 2012. ${ }^{176}$ The NEB would, at that time, then consider whether the tariff is "just and reasonable." In the event that stakeholders remain interested in challenging whether a change to a receipt point convention is in the public interest, then such a challenge could be launched in the context of the NEB's tariff proceedings. One question that will be raised at that time is whether the findings and recommendations of the Inquiry Decision remain valid in light of the arguably different public interest test that would be considered by an Alberta regulator, as opposed to a federal regulator such as the NEB. Those who remain supportive of the NEXT Model will argue that the findings of the Inquiry Decision ought to be respected by the NEB.

Presumably, during its deliberations the EUB considered the fact that a change in jurisdiction over the NGTL System might be forthcoming, but this possible change did not have a discernible impact on its recommendations. For example, in its recommendation that NGTL conduct a confidential survey of stakeholders in the extraction rights market two years after the NEXT Model is implemented to determine whether a competitive, transparent market has developed, ${ }^{177}$ the EUB went on to say that necessary adjustments would have to

Ibid. at 105-107.

Supra note 2.

Ibid. at 9.

Ibid. at 28.

R.S.C. 1985, c. N-7.

National Energy Board, Certificate GC-113 (15 April 2009), online: NEB <https://www.nebone.gc.ca/ll-eng/livelink.exe/fetch/2000/90464/90550/554112/554219/554220/551476/553396/ A1J4K0_-_Certificate_GC-113.pdf?nodeid=553400\&vernum=0>.

Inquiry Decision, supra note 1 at 86.

Ibid. at 87. 
be taken up with “the appropriate regulator(s).” ${ }^{178}$ This may have been written with either the AUC or NEB in mind.

\section{POST-INQUIRY DEVELOPMENTS AND EXPECTATIONS}

As noted, the Inquiry Decision contained three categories of recommendations, the first relating to modification of existing NGL extraction rights allocation protocols and practices, with particular focus on the Current NGTL Convention, the second relating to lean gas streaming initiatives, and the third relating to the approach that should be taken with respect to future side-streaming and co-streaming proposals. The first category of recommendations is expected to generate the most near-term activity, but the recent AltaGas/Taylor application for approval of a Harmattan Plant co-streaming project (the Harmattan Co-Streaming Application $)^{179}$ can be expected to garner significant attention as well.

\section{A. NGTL CONVENTION Modification}

\section{PROCESS}

NGTL is proceeding on the EUB's recommendation to incorporate the NEXT Model, or such modified version thereof as may result from the stakeholder consultation process (the Modified NEXT Protocol), in the NGTL Tariff by February 2012. Current thinking is that the TTFP will be presented with a proposal to create a new task force for this purpose before the end of the summer, and that this task force will be given the mandate of gathering and assessing stakeholder input and making recommendations based thereon, with a view to allowing NGTL to be in a position to file a tariff amendment application with the NEB in the first half of 2010. Subject to timely completion of the task force and regulatory approval processes, NGTL hopes to implement the Modified NEXT Protocol by the beginning of the gas year on 1 November 2011. In keeping with the EUB's recommendations, NGTL has also committed to undertake a confidential survey of stakeholders two years following implementation in order to assess perspectives on the effectiveness of the Modified NEXT Protocol. ${ }^{180}$

\section{NEXT MODEL OVERVIEW}

The NEXT Model was designed to accommodate a change from delivery shipper extraction contracting to receipt shipper extraction contracting with minimal cost and minimal disruption of existing operational and administrative practices and procedures. Under the NEXT Model only receipt shippers will have NGL extraction rights, ${ }^{181}$ and for purposes of giving effect to those rights each receipt shipper (a Shipper) will be allocated a "Monthly NEXT Allocation Percentage" (an Allocation Percentage) to be determined as follows:

Ibid.

Supra note 73.

Inquiry Decision, supra note 1 at 87.

Ibid. at 44 . 
- At each receipt point on the NGTL System, gas delivered into the system will be measured for its "In-Stream Components" (ISCs), with each of the four principal NGL constituents (i.e. ethane, propane, butane, and pentanes plus) measured and tracked separately. The ISCs as so measured will then be attributed proportionately to each Shipper delivering gas into the system at that receipt point.

- $\quad$ For each calendar month in which a Shipper delivers gas into the system (a "Determination Month"), the "Total ISC Value” of all such gas will be determined by first multiplying (i) the total amount of each category of ISC delivered into the system by that Shipper during that month, by (ii) the Alberta Department of Energy Reference Price for that particular category of ISC for that month, and by then adding the four products so obtained, as follows:

\section{Total Shipper $\mathrm{C}_{2}$ deliveries $\times \mathrm{C}_{2}$ Reference Price $=\$ \mathrm{~A}$ \\ Total Shipper $\mathrm{C}_{3}$ deliveries $\mathrm{x}_{3}$ Reference Price $=\$ \mathrm{~B}$ \\ Total Shipper $\mathrm{C}_{4}$ deliveries $\mathrm{x} \mathrm{C}_{4}$ Reference Price $=\$ \mathrm{C}$ \\ Total Shipper $\mathrm{C}_{5}+$ deliveries $\mathrm{x}_{5}+$ Reference Price $=\$ \mathrm{D}$}

Shipper's Total ISC Value $=\$ A+\$ B+\$ C+\$ D$

- $\quad$ Each Shipper's Total ISC Value for a Determination Month will be calculated within 20 days following the end of that month and will be used to set that Shipper's Allocation Percentage for the second month following the Determination Month (the “Extraction Month”). Each Shipper's Allocation Percentage for an Extraction Month will be the percentage expression of the ratio of (i) that Shipper's Total ISC Value for the correlative Determination Month, to (ii) the total of all Shippers' Total ISC Values for that Determination Month, such that the total of all Allocation Percentages for any Extraction Month will be 100 percent.

- A Shipper's Allocation Percentage for an Extraction Month will entitle it to process a corresponding percentage of the gas flowing past NGTL System straddle plants on each day during that Extraction Month. It is expected that Shippers will typically transfer this entitlement to one or more straddle plant operators under one or more Extraction Contracts, and will then notify NGTL of each transfer of entitlement by way of a "banding instruction," similar to the banding instructions that are currently provided to NGTL by delivery shippers under the Current NGTL Convention.

- $\quad$ NGTL will rely on Shippers' banding instructions to authorize diversion of system gas to the respective straddle plants for extraction processing. Since it is unlikely that there will be a precise match between Shipper banding instructions and the quantities of gas flowing past the inlet of each of the six straddle plants on any day, NGTL anticipates the development of a secondary market through which Shippers and/or straddle plant operators will be able to balance extraction entitlement with gas flow through further transfers of extraction entitlement. The operation and implementation details for this secondary market will be developed through the stakeholder consultation process. 


\section{DISCUSSION ITEMS}

Although the EUB concluded that the NEXT Model provides the most appropriate platform for a new NGTL System extraction rights protocol to replace the Current NGTL Convention, it also recognized a need for further stakeholder consultation to refine the NEXT Model to generate the Modified NEXT Protocol to be submitted for regulatory approval. ${ }^{182}$ Among the issues expected to be subject to further discussion in this consultation process are:

(1) Inaccessible gas: In the Inquiry Decision, the EUB noted that the NEXT Model fails to address a type of "double dipping" inequity, ${ }^{183}$ in that it gives Shippers credit for ISCs entrained in gas that is delivered into segments of the NGTL System that are not serviced by a straddle plant. Since this gas does not have access to a straddle plant, and accordingly cannot be subjected to extraction processing before being delivered out of the system, it is arguably both inequitable and illogical to provide extraction rights credit for the ISCs entrained in that gas. The EUB stated that it was satisfied with NGTL's assessment that “this inequity is not material," but also noted in this respect that "the NEXT Model is flexible and it can be modified in the future, if necessary." 184

(2) Component tracking: Although the component tracking feature of the CCM Model would provide a more precise ISC allocation methodology than the extraction rights allocation methodology under the NEXT Model, the EUB concluded that there was not enough information with respect to either the operational detail or the cost of a component tracking approach to endorse the CCM Model. ${ }^{185}$ However, the EUB also noted that Imperial/EMC, the principal CCM Model proponent, was not foreclosed from pursuing a component tracking "enhancement” to the NEXT Model. ${ }^{186}$ Although NGTL believes that the cost and complexity associated with component tracking outweighs its benefits, the matter could be revisited.

(3) Adjustment for stream richness: Given variations in the richness of the gas streams available to different straddle plants, a Shipper whose Allocation Percentage is applied to a richer gas stream will receive greater relative benefit than a Shipper whose Allocation Percentage is applied to a leaner gas stream. This inequity could perhaps be alleviated by allocating system ISC volumes rather than system gas volumes, although this might involve more administrative effort, particularly in the area of balancing/reconciliation.

(4) Matching banding instructions to physical flow: As long as NGL extraction is economic it will be desirable from both public interest and private commercial perspectives to ensure that all economically processable gas flowing by a straddle plant can be accessed for processing. It will accordingly be important to ensure that

Ibid. at 87.

Ibid. at 84 .

Ibid.

Ibid. at 82.

Inquiry Transcript, supra note 100, at 83, Volume 20, at 2991, 2920. 
the Modified NEXT Protocol will have the flexibility to accommodate the ready adjustment of banding instructions to ensure that Allocation Percentages will not go unused as a result of disproportionate assignments of Allocation Percentages among the straddle plants.

(5) Fairness Check: There will be a need to confirm that the Allocation Percentage determination methodology is in fact balanced and fair, and not susceptible to abuse. For example, given that a Shipper's Allocation Percentage for any month is based on its ISC deliveries in a previous month, is there opportunity for a Shipper with a field extraction alternative to manage its deliveries of ISCs into the NGTL System so as to provide itself with both a full Allocation Percentage and field extracted NGLs in months in which it anticipates particularly favourable NGL margins?

(6) Fostering a competitive, transparent market: NGTL will be seeking further stakeholder input on ways in which to improve the competitiveness and transparency of NGL extraction rights marketing, ${ }^{187}$ and is prepared to accommodate an electronic trading system if someone wishes to develop one, but does not plan to develop an electronic trading system itself.

(7) Accommodation of right to take in kind: NGTL is of the view that the NEXT Model already accommodates taking in kind by Shippers, and that this is simply a matter of the Shipper entering into a toll processing arrangement with a straddle plant operator and issuing banding instructions accordingly. ${ }^{188}$

There is also the possibility of further regulatory challenge with respect to the weight that the EUB's recommendations should be given in an NEB tariff amendment process.

\section{IMPLICATIONS FOR AFFECTED PARTIES}

Assuming that NGTL implements a Modified NEXT Proposal substantially the same as the NEXT Model, some of the implications may be as follows:

(1) Economic benefit shifts: The participants in the Inquiry were fairly uniformly of the view that a change from delivery shipper contracting to receipt shipper contracting can be expected to result in a "transfer of wealth" from the delivery shipper group to the receipt shipper group. ${ }^{189}$ Because the value of extraction rights has not historically been reflected in NIT pricing, receipt shippers have not as such participated in that value in any significant way, but they will now be able to receive it directly and will also be in a position to negotiate different ways of determining and realizing that value. 
It was also suggested by some Inquiry participants that a change from delivery shipper contracting to receipt shipper contracting could be expected to result in a "transfer of wealth" away from straddle plant operators as straddle plant margins narrow in response to enhanced competition. ${ }^{190}$ At present, there are roughly 90 export point delivery shippers and 135 receipt shippers on the NGTL System, with four of the five largest shippers holding both receipt and delivery service, ${ }^{191}$ so this wealth transfer conclusion would not seem to be justified by the relative shipper numbers alone. However, in combination with declining straddle plant utilization rates, an EUB direction to foster a more competitive and transparent extraction rights market, and the possibility of the development of electronic trading in connection therewith, a tightening of straddle plant margins and resultant redistribution of economic benefit away from the straddle plants would be a reasonable expectation.

(2) Plant utilization adjustments: All else being equal, a shift to receipt shipper contracting combined with anticipated improvements in the accessibility of market information should lead to more efficient utilization of extraction infrastructure, with producers being positioned to balance the use of field extraction and straddle plant extraction having regard to which makes more economic and logistical sense from time to time. Similarly, in the case of extraction at Empress, where there are extraction alternatives and thus competition, volumes should in theory be directed first to the most efficient plants. Given the worsening underutilization situation at Empress, this could in due course lead to some mothballing of less efficient facilities.

(3) Contracting practices: Even if an electronic extraction rights trading system is developed, it is likely that a very significant amount of extraction rights contracting will continue to be handled by way of direct Extraction Contracts, similar to the experience in the gas marketing business. In order to simplify the contracting process it is also likely that a standard form of Extraction Contract will be developed in due course, likely with flexibility to negotiate creative compensation terms. Having regard to the proposed process for realizing value out of Allocation Percentages, there may also be some movement away from the traditional discretionary processing approach toward some form of firm or minimum processing commitment, perhaps coupled with an option to make a payment in lieu of processing. The combination of simplified contracting processes and increased competition and transparency may also result in a trend toward shorter terms for Extraction Contracts. For those receipt shippers that do not have the resources or inclination to develop expertise in extraction rights marketing, there may be opportunities for extraction rights aggregators or managers to become more actively involved in the market.

(4) Pricing: As noted, it is expected that increased competition and market information availability will put downward pressure on straddle plant margins, with a

Interview by D. Guichon of G. Milne, Business Analyst, TransCanada Pipelines Limited (June 2009). 
corresponding increase in the prices paid for extraction rights, all else being equal. In the case of ethane, for which little or no premium compensation has historically been paid under traditional Extraction Contracts, the evolution of the basis on which ethane is paid for by ethane buyers could result in a more common inclusion of an ethane premium in the cash component of the compensation paid under Extraction Contracts.

(5) Toll Processing: In order to effectively exercise the right to take in kind advocated by Imperial/EMC and ultimately endorsed by the EUB, a receipt shipper would require access to extraction services, or "toll processing," at a straddle plant. If the shipper was unable to negotiate acceptable terms for toll processing, it could pursue a common processor designation for the straddle plant, and if it was successful in that respect the provision of extraction services by the straddle plant would then become subject to regulation. It will be interesting to see how this plays out.

(6) Northern gas draw: Time will tell how much of a factor receipt shipper contracting will be in attracting Northern gas to Alberta's natural gas transportation and processing infrastructure.

\section{B. ATCO SySTEM EXTRACTION Rights PROTOCOL}

Although the EUB prompted ATCO Pipelines to undertake a review of the "continuing appropriateness" of its current extraction rights protocol, ${ }^{192}$ the pursuit of that review has been deferred pending a determination of the outcome of a proposal to integrate the operation of the NGTL System and the ATCO System, such that service on the two systems could be provided on a "seamless" basis under a single consolidated service arrangement. The intention to pursue this integration was announced by NGTL and ATCO Pipelines in September 2008, ${ }^{193}$ between completion of the Inquiry hearing and the issuance of the Inquiry Decision. It is expected that applications to approve the integration proposal will be filed imminently, and NGTL and ATCO Pipelines are currently targeting integration implementation in the first quarter of $2011,{ }^{194}$ prior to the targeted implementation timeframe for the Modified NEXT Protocol. If the proposed integration is approved and implemented, it is expected that the Modified NEXT Protocol will apply on a consolidated basis with respect to all gas and all straddle plants on the two systems. If that is the case, consideration will of course need to be given to the potential ramifications of introducing three additional mid-system straddle plants to the Modified NEXT Protocol mix.

\section{$192 \quad$ Ibid. at 87.}

193 Canadian Utilities Limited, News Release, “TransCanada (NGTL) and Canadian Utilities Limited (ATCO Pipelines) Reach Proposed Agreement to Provide Seamless Alberta Natural Gas Transmission Service” (8 September 2008), online: Canadian Utilities <http://cnrp.marketwire.com/cnrp_files/ 20081024-908trp.pdf>; TransCanada Corporation, News Release, “TransCanada (NGTL) and Canadian Utilities Limited (ATCO Pipelines) Reach Proposed Agreement to Provide Seamless Alberta Natural Gas Transmission Service” (8 September 2008), online: TransCanada <http://www.transcanada.com/ news/2008_news/20080908.html>. 


\section{Lean Gas Streaming}

Although NGTL is planning to comply with the EUB's recommendation that it cause a TTFP task force to be formed to prepare a report on lean gas streaming, with a view to issuing that report by 1 April 2010, ${ }^{195}$ the formation of this task force will not likely occur until later this year, once the TTFP has addressed a number of other pressing issues.

\section{SidE-STREAMING AND CO-STREAMING}

As noted above, the EUB concluded in the Inquiry Decision that it would be preferable to deal with side-streaming and co-streaming applications on a case-by-case basis, without a predetermined prescriptive list of approval criteria, but subject to some points of "general recommended guidance.” ${ }^{196}$ The Harmattan Co-Streaming Application ${ }^{197}$ will provide the first opportunity to consider this general recommended guidance. Of note in this respect is that this application has been made to the ERCB; no NEB involvement is expected to be required in that NGTL would simply be accommodating diversion of gas for extraction processing on the same basis as for other straddle plants. Current expectations are that a hearing on the application will be held in late 2009, and that a decision should be forthcoming by the end of 2009 or early in 2010 . 